\title{
Two Emissive Long-lived Excited States of an Imidazole-functionalized Ruthenium Dipyridophenazine Complex
}

Dajana Isakov ${ }^{\dagger}$, Robin Giereth $^{\dagger}$, Djawed Nauroozi, Stefanie Tschierlei, * and Sven Rau*

Ulm University, Institute of Inorganic Chemistry I, Albert-Einstein-Allee 11, 89081 Ulm, Germany.

E-mail: sven.rau@uni-ulm.de; stefanie.tschierlei@uni-ulm.de

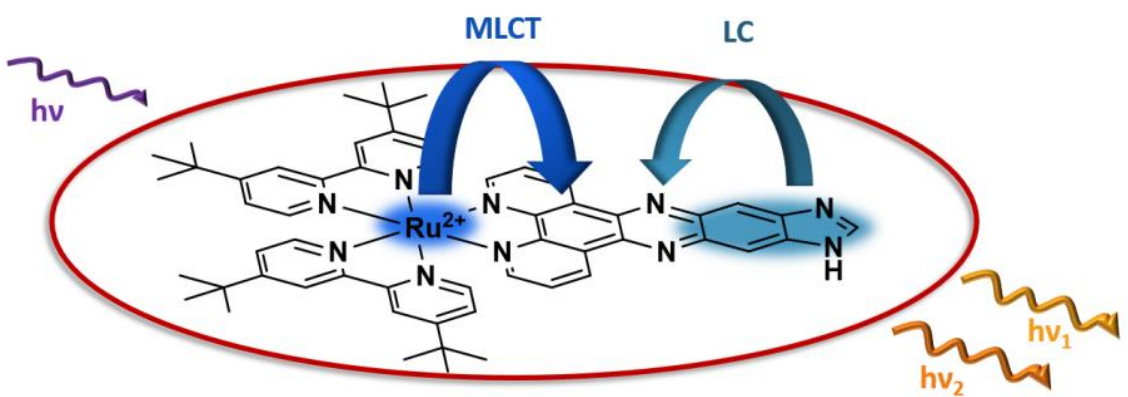

\section{Supporting Information - Table of Contents}

1 Experimental Details

page $\quad$ S2

2 Synthetic Details

page S4

3 Structural Characterization of $\mathbf{C 1}$

page $\mathrm{S} 6$

3.1. NMR Spectra

3.2. MS Spectra

3.3. Concentration Dependent NMR Studies

$4 \quad$ UV/Vis and Emission Data

page S11

4.1. UV/Vis and Emission Data of $\mathbf{C 1}$

4.2. Photostability of $\mathbf{C O}$ and $\mathbf{C 1}$

4.3. Luminescence Quenching Studies

5 Calculated Ground State Structure of C1

page $\mathrm{S} 17$

6 TD-DFT Calculations of $\mathbf{C 1}$

page $\mathrm{S} 18$

7 Emission Lifetime Measurements

page $\quad$ S20

8 Nanosecond Transient Absorption Measurements

page $\$ 23$ 


\section{NMR spectroscopy}

NMR spectra were recorded on a Bruker Avance $400 \mathrm{MHz}$, or a Bruker Avance $500 \mathrm{MHz}$, at $298 \mathrm{~K}$ and processed with MestreNova software (version 12.0.0). The chemical shifts $\delta$ are reported in parts per million (ppm). ${ }^{1} \mathrm{H}$ - and ${ }^{13} \mathrm{C}-\mathrm{NMR}$ shifts are referenced using the deuterated solvent as an internal standard. ${ }^{1}$ Coupling constants $J$ are presented as absolute values in $\mathrm{Hz}$. For the characterization of the NMR signals the following abbreviations are used: $s=$ singlet,$d=$ doublet, $m=$ multiplet and $d d=$ doublet of doublets.

\section{Mass spectrometry}

ESI-MS values are given as $m / z$. Mass spectrometric measurements were performed by the analytical service of the Institute for Organic Chemistry II at the University of Ulm using electrospray ionization on a Bruker solariX Hybrid 7T FT-ICR.

\section{Steady-state absorption and emission spectroscopy}

Steady-state UV/vis absorption spectra were recorded with a JASCO V-670 spectrophotometer and emission spectra were measured with a JASCO FP-8500 spectrofluorometer. For measurements under air in acetonitrile and methanol, ROTISOLV, UV/vis/IR grade solvents purchased from Carl Roth were used. For measurements performed in air in dichloromethane, solvent with $>99.9 \%$ purity grade purchased from Carl Roth was used. The water titration experiments were carried out in degassed, anhydrous acetonitrile from a MB-SPS-800 solvent purification system. The stock solutions were prepared under an argon atmosphere using schlenk techniques. For the preparation of the samples, cuvettes with a pathlength of $10 \mathrm{~mm}$ were placed in a schlenk tube and placed under an argon atmosphere. Relative emission quantum yields were derived from the integrated area of emission in comparison to $\left[\mathrm{Ru}(\mathrm{bpy})_{3}\right]\left(\mathrm{PF}_{6}\right)_{2}$ as reference compound $\left(\Phi=0.06\right.$ in degassed acetonitrile $\left.{ }^{2}\right)$, detected at an excitation wavelength of $441 \mathrm{~nm}$.

\section{Photostability tests}

UV/vis absorption spectra were recorded with a JASCO V-670 spectrophotometer. Homebuilt blue LEDsticks $(P=45 \mathrm{~mW}$ ) were used to irradiate the sample with $470 \mathrm{~nm}$ light. The measurements were carried out under inert conditions. For the sample solutions degassed, anhydrous acetonitrile, or degassed acetonitrile-water mixtures (v:v / 9:1) were used. The preparation of the samples was carried out using the method as that used for absorption and emission spectroscopy with closed cuvettes with a pathlength of $10 \mathrm{~mm}$. To maintain room temperature $\left(22^{\circ} \mathrm{C}\right)$ during irradiation, the cuvettes were cooled by vents in a homebuilt reactor. ${ }^{3}$ For irradiation in the UV-Vis range a xenon arc lamp (150 W) from LOT Quantum Design was used.

\section{Nanosecond transient absorption spectroscopy}

A Q-switched pulsed Nd:YAG laser (Q-smart $450 \mathrm{~mJ}$, Quantel laser) was used to generate excitation pulses with an output centered at $355 \mathrm{~nm}$ (approx. $6 \mathrm{~ns}$ pulse duration. repetition rate of $10 \mathrm{~Hz}$ ). These pulses were passed through a laser line filter $(C W L=355 \pm 2 \mathrm{~nm}, \mathrm{FWHM}=10 \pm 2 \mathrm{~nm}$ ) to ensure that the samples were only excited by $355 \mathrm{~nm}$ light. The power of the pump beam was maintained at about $5 \mathrm{~mJ}$ per pulse at the sample. To prevent potential damage of the samples by UV light a $400 \mathrm{~nm}$ longpass filter was used and the stability of the sample was verified by means of UV/vis spectra before and after each measurement. The spectrometer used was a LP980-K spectrometer from Edinburgh Instruments, where the pump and probe beams spatially overlapped at the sample position in a perpendicular beam setup. The probe lamp was operated in flash mode ( $150 \mathrm{~W}$ ozone-free xenon arc lamp, $30 \mathrm{~A}$ ), and after passing the sample the probe light was recorded using a photo multiplier tube (Hamamatsu R928P). A standard fused silica cuvette

\footnotetext{
${ }^{1}$ H. E. Gottlieb, V. Kotlyar, A. Nudelman, J. Org. Chem., 1997, 62, 7512-7515.

2 J. V. Caspar, T. J. Meyer, J. Am. Chem. Soc. 1983, 105, 5583-5590.

${ }^{3}$ M. G. Pfeffer, T. Kowacs, M. Wächtler, J. Guthmuller, B. Dietzek, J. G. Vos, S. Rau, Angew. Chem. Int. Ed., 2015, 54, 6627-6631.
} 
with a layer thickness of $10 \mathrm{~mm}$ and a sample OD of approximately 0.12 at the pump wavelength of 355 $\mathrm{nm}$ was used in this setup. The compound $\mathbf{C 1}$ was dissolved in extra dry acetonitrile (VWR Chemicals BDH Prolabo, water $\leq 10 \mathrm{ppm}$ ) under inert conditions in an argon filled glovebox. The solvent was also degassed via freeze pump thaw treatment, prior to use.

Emission lifetime measurements were performed with the same setup as described above. Identical conditions for the preparation of the samples were used to ensure comparability of the measurements. The power of the pump beam was about $2.5 \mathrm{~mJ}$ per pulse at the sample.

Cyclic voltammetry was carried out in anhydrous, degassed acetonitrile with $0.1 \mathrm{M} \mathrm{Bu}_{4} \mathrm{NPF}_{6}$ as the supporting electrolyte. The measurements were performed with a $\mathrm{CH}$ Instruments $620 \mathrm{E}$ electrochemical workstation using a three-electrode configuration: a glassy carbon electrode $(\mathrm{d}=1.6 \mathrm{~mm})$ as working electrode, a Pt wire as the counter electrode and a Ag wire as a quasi-reference electrode (in a glass frit, which contained the electrolyte with the same concentration as the electrolyte in the analyzed solution). Ferrocene/ferricenium $\left(\mathrm{Fc} / \mathrm{Fc}^{+}\right)$was used as a parallel standard and was added to the solution after each measurement. Thus, all reported potentials are versus the $\mathrm{Fc} / \mathrm{Fc}^{+}$couple. Unless otherwise stated, the voltammograms were recorded at a scan rate of $0.2 \mathrm{~V} / \mathrm{s}$.

\section{DFT calculations.}

Simulations at the density functional theory (DFT) level were performed using the ORCA program package (Version 4.0.1.2). ${ }^{4}$ For geometry optimizations of the electronic ground state, the BP86 exchangecorrelation functional was used ${ }^{8}$. Excited state calculations were carried out with the B3-LYP functional, starting from ground state structures (with methyl groups instead of tert.-butyl substituents to limit the calculation time) optimized with the B3-LYP functional. ${ }^{5}$ To account for dispersion effects, the DFTD3 V3.1 correction (D3) by S. Grimme including the Becke-Johnson (BJ) damping is used throughout all B3LYP calculations. ${ }^{6}$ As basis sets the triple zeta valance plus polarization functions (def2-TZVP) were used. ${ }^{7}$ Solvation effects were accounted for by the conductor-like polarizable continuum model, CPCM, with an appropriate dielectric constant and refractive index of acetonitrile. ${ }^{8}$

All stationary points on the potential energy surface of the $S_{0}$ state were verified by calculations of the energy second derivatives with respect to nuclear coordinates. For the calculation of excited states at the time-dependent density functional theory level, the Tamm-Dancoff approximation (tda-TD-DFT) was used. Visualizations of the B3-LYP molecular orbitals and of the electron density difference maps were made with IboView v20150427 and Jmol, respectively. ${ }^{9,10}$

\footnotetext{
a) F. Neese, WIREs Comput. Mol. Sci., 2017, 8 b) F. Neese, Interdiscip. Rev. Comput. Mol. Sci., 2012, 2, 73.

O. Treutler, R. Ahlrichs, J. Chem. Phys., 1995, 102, 346-354.

a) S. Grimme, J. Antony, S. Ehrlich, H. Krieg, J. Chem. Phys., 2010, 132, 154104. b) S. Grimme, S. Ehrlich, L. Goerigk, J. Comput. Chem., 2011, 32, 1456.

7 F. Weigend, R. Ahlrichs, Phys. Chem. Chem. Phys., 2005, 7, 3297-3305.

8 V. Barone, M. Cossi, J. Phys. Chem. A, 1998, 102, 1995.

9 G. Knizia, J. Chem. Theory Comput., 2013, 9, 4834-4883.

10 http://www.jmol.org/
} 
Chemicals were purchased from commercial suppliers (e.g. Fluka/Sigma/Aldrich, Alfa Aeser, Merck, VWR, Acros or $A B C R$ ) and, unless otherwise noted, used as received. Compounds $1-4^{11}, 1,10$-Phenanthroline5,6-dione ${ }^{12},\left[(\text { tbbpy })_{2} \mathrm{RuCl}_{2}\right]^{13},\left[(\mathrm{tbbpy})_{2} \mathrm{Ru}(\mathrm{dppz})\right]\left(\mathrm{PF}_{6}\right)_{2}{ }^{14}$ and $\mathbf{L 1}^{15}$ were synthesized according to previously published literature procedures.

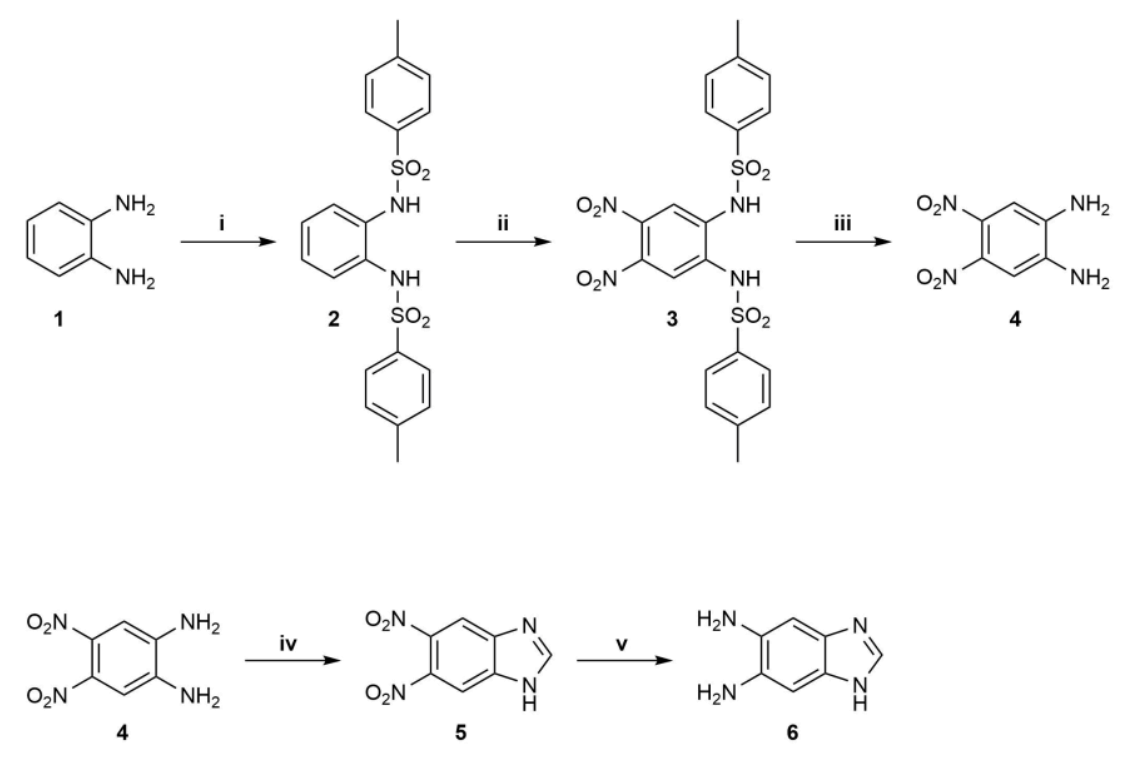

Scheme S12.1. Synthesis of the compounds 1-6. (i-iii: according to literature ${ }^{10}$; iv: $\mathrm{CHOOH}$; $3 \mathrm{~h}$, reflux; v: $\mathrm{N}_{2} \mathrm{H}_{4} \mathrm{xH}_{2} \mathrm{O}, \mathrm{Pd} / \mathrm{C}, \mathrm{EtOH}, 24 \mathrm{~h}$, reflux).

\section{5,6-Dinitrobenzimidazole (5)}

A solution of $1.025 \mathrm{~g}$ ( $6.31 \mathrm{mmol})$ of 4 in $25 \mathrm{~mL}$ of formic acid was heated at reflux for $3 \mathrm{~h}$. After cooling to room temperature, the solution was poured onto $350 \mathrm{~mL}$ of an ice-water-mixture. The resulting precipitate was collected by filtration and washed two times with $25 \mathrm{~mL}$ demineralized water then allowed to dry under air. Yield: $922 \mathrm{mg}(4.43 \mathrm{mmol}, 70 \%)$ of 5.

${ }^{1} \mathrm{H}-\mathrm{NMR}\left(400 \mathrm{MHz},\left(\mathrm{CD}_{3}\right)_{2} \mathrm{SO}\right): \delta=8.77(\mathrm{~s}, 1 \mathrm{H}), 8.49(\mathrm{~s}, 2 \mathrm{H})$.

\section{5,6-Diaminobenzimidazole (6)}

A mixture of $1.064 \mathrm{~g}(5.11 \mathrm{mmol})$ of 5 and $0.544 \mathrm{~g}$ of $\mathrm{Pd} / \mathrm{C}(10 \mathrm{w} \%, 0.51 \mathrm{mmol} \mathrm{Pd})$ in $75 \mathrm{~mL}$ ethanol was heated to reflux. A solution of $7.5 \mathrm{~mL}(154.32 \mathrm{mmol})$ of hydrazine monohydrate in $25 \mathrm{~mL}$ ethanol was added to the hot suspension over the course of ten minutes. The reaction mixture was then heated at reflux for $24 \mathrm{~h}$. After separating the $\mathrm{Pd} / \mathrm{C}$ by filtration of the hot suspension, the solvent was removed under reduced pressure. The residue was taken up in $20 \mathrm{~mL}$ of ethanol then $120 \mathrm{~mL}$ of water was added. The solution was concentrated by solvent removal under reduced pressure until precipitation of the product occurred. The product was collected by filtration then washed two times with $25 \mathrm{~mL}$ water, two times with $25 \mathrm{~mL}$ diethyl ether, and dried under reduced pressure. Cooling the mother liquor allowed a second fraction of the product to be obtained. Yield: $423 \mathrm{mg}(2.72 \mathrm{mmol}, 56 \%)$ of 6 .

${ }^{1} \mathrm{H}-\mathrm{NMR}\left(400 \mathrm{MHz},\left(\mathrm{CD}_{3}\right)_{2} \mathrm{SO}\right): \delta=11.60(\mathrm{~s}, 1 \mathrm{H}), 7.68(\mathrm{~s}, 1 \mathrm{H}), 6.72(\mathrm{~s}, 2 \mathrm{H}), 4.30(\mathrm{~s}, 4 \mathrm{H})$.

11 G. W. H. Cheeseman, J. Chem. Soc., 1962, 0, 1170-1176.

12 a) J. Bolger, A. Gourdon, E. Ishow, J-P. Launay, J. Chem. Soc., Chem. Commun., 1995, 0, 1799-1800.; b) C. Hiort, P. Lincoln, B. Norden, J. Am. Chem. Soc., 1993, 115, 3448-3454.

13 S. Rau, B. Schäfer, A. Grüßing, S. Schebesta, K. Lamm, J. Vieth, H. Görls, D. Walther, M. Rudolph, U. W. Grummt, E. Birkner, Inorg. Chim. Acta, 2004, 357, 4496-4503.

14 C. Kuhnt, M. Karnahl, S. Tschierlei, K. Griebenow, M. Schmitt, B. Schäfer, S. Krieck, H. Görls, S. Rau, B. Dietzek, J. Popp, Phys. Chem. Chem. Phys., 2010, 12, 1357-1368.

15 S. Shi, J. Zhao, X. Gao, C. Lv, L. Yang, J. Hao, H. Huang, J. Yao, W. Sun, T. Yao, L. Ji, Dalton Trans., 2012, 41, 57895793. 


\section{$\left[(\text { tbbpy })_{2} \mathrm{Ru}\left(\right.\right.$ phenO $\left.\left._{2}\right)\right] \mathrm{Cl}_{2}\left(\mathrm{Ru}\left(\right.\right.$ phenO $\left.\left._{2}\right)\right)$}

An ethanol-water-mixture (v:v / 3:2, $200 \mathrm{~mL})$ was added to $407 \mathrm{mg}(0.573 \mathrm{mmol})$ of [(tbbpy $\left.)_{2} \mathrm{RuCl}_{2}\right]$ and $120 \mathrm{mg}(0.571 \mathrm{mmol})$ of 1,10-phenthroline-5,6-dione. The mixture was heated to reflux in a microwave oven (i: $5 \mathrm{~min}, 145 \mathrm{~W}$; ii: $1.5 \mathrm{~h}, 140 \mathrm{~W}$ ). After removing the solvent under reduced pressure, the residue was taken up in $20 \mathrm{~mL}$ of ethanol then $200 \mathrm{~mL}$ of diethyl ether was added slowly. The resulting precipitate was collected by filtration and further purified via size exclusion chromatography (Sephadex-LH 20, eluent: methanol). Yield: $359 \mathrm{mg}(0.391 \mathrm{mmol}, 68 \%)$.

${ }^{1} \mathrm{H}-\mathrm{NMR}\left(400 \mathrm{MHz}, \mathrm{CD}_{3} \mathrm{CN}\right): \delta=8.53(\mathrm{~d}, J=1.8 \mathrm{~Hz}, 4 \mathrm{H}), 8.47(\mathrm{~d}, J=8.0 \mathrm{~Hz}, 2 \mathrm{H}), 7.87(\mathrm{~d}, J=5.2 \mathrm{~Hz}, 2 \mathrm{H}), 7.80$ $(\mathrm{d}, J=6.1 \mathrm{~Hz}, 2 \mathrm{H}), 7.59(\mathrm{~d}, J=5.6 \mathrm{~Hz}, 2 \mathrm{H}), 7.57(\mathrm{~d}, J=5.6 \mathrm{~Hz}, 2 \mathrm{H}), 7.41(\mathrm{~m}, 4 \mathrm{H}), 1.41(\mathrm{~s}, 18 \mathrm{H}), 1.40(\mathrm{~s}, 18 \mathrm{H})$.

\section{[(tbbpy) ${ }_{2} \mathrm{Ru}$ (di)] $\mathrm{Cl}_{2}$ (chloride salt of C1)}

$63 \mathrm{mg}(0.068 \mathrm{mmol})$ of $\mathrm{Ru}\left(\right.$ phen $\left._{2}\right)$ and $13 \mathrm{mg}(0.088 \mathrm{mmol})$ of 6 were dissolved in methanol and heated at reflux for $20 \mathrm{~h}$. The solvent was then removed under reduced pressure and the residue was purified via size exclusion chromatography (Sephadex-LH 20, eluent: methanol). Yield: $54 \mathrm{mg}(0.052 \mathrm{mmol}, 77 \%)$ of the chloride salt of $\mathbf{C 1}$.

Counter ion exchange:

For counter ion exchange $54 \mathrm{mg}$ of the chloride salt of $\mathbf{C 1}$ was dissolved in $2 \mathrm{~mL}$ of methanol and a saturated solution of 10 eq. of $\mathrm{NH}_{4} \mathrm{PF}_{6}$ was added. The resulting, precipitate was extracted into dichloromethane, and the organic phase was washed with $\mathrm{mL}$ demineralized water. After separation of the aqueous phase, the organic phase was dried over $\mathrm{MgSO}_{4}$, filtrated and the solvent was removed under reduced pressure. Yield: $49 \mathrm{mg}(0.039 \mathrm{mmol}, 75 \%)$ of the $\mathrm{PF}_{6}$-salt of $\mathbf{C 1}$.

${ }^{1} \mathrm{H}$ NMR $\left(400 \mathrm{MHz}, \mathrm{CD}_{3} \mathrm{CN}\right): \delta=11.27(\mathrm{~s}, 1 \mathrm{H}), 9.62(\mathrm{dd}, J=8.2,1.3 \mathrm{~Hz}, 2 \mathrm{H}), 8.71(\mathrm{~s}, 1 \mathrm{H}), 8.56(\mathrm{~s}, 2 \mathrm{H}), 8.54(\mathrm{~d}$, $J=1.7 \mathrm{~Hz}, 2 \mathrm{H}), 8.50(\mathrm{~d}, J=1.7 \mathrm{~Hz}, 2 \mathrm{H}), 8.10(\mathrm{dd}, J=5.4,1.3 \mathrm{~Hz}, 2 \mathrm{H}), 7.88(\mathrm{dd}, J=8.2,5.4 \mathrm{~Hz}, 2 \mathrm{H}), 7.70(\mathrm{~d}, J$ $=5.9 \mathrm{~Hz}, 2 \mathrm{H}), 7.63(\mathrm{~d}, J=5.9 \mathrm{~Hz}, 2 \mathrm{H}), 7.48(\mathrm{dd}, J=6.1,2.0 \mathrm{~Hz}, 2 \mathrm{H}), 7.25(\mathrm{dd}, J=6.1,2.0 \mathrm{~Hz}, 2 \mathrm{H}), 1.45(\mathrm{~s}, 18$ $\mathrm{H}), 1.35(\mathrm{~s}, 18 \mathrm{H})$.

${ }^{13} \mathrm{C}$ NMR $\left(126 \mathrm{MHz}, \mathrm{CD}_{3} \mathrm{CN}\right): \delta=163.79,163.67,158.11,157.88,153.92,152.47,152.10,151.51,151.03$, $140.04,139.26,133.84,132.14,128.28,125.71,125.57,122.63,122.54$.

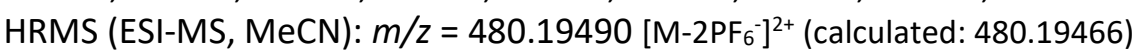

\section{$\left[(\mathrm{MeCN})_{2} \mathrm{Zn}(\mathrm{di})\right]\left(\mathrm{BF}_{4}\right)(\mathrm{ZnL} 1)$}

i) Synthesis of $\mathbf{L 1}$

$30 \mathrm{mg}(0.143 \mathrm{mmol})$ of 1,10-phenanthroline-5,6-dione and $22 \mathrm{mg}(0.148 \mathrm{mmol})$ of 6 , were suspended in 10 $\mathrm{mL}$ of methanol and heated to reflux for $2 \mathrm{~h}$. The precipitate was filtered off and washed two times with $25 \mathrm{~mL}$ of chloroform. The product was directly used for the subsequent complexation reaction.

ii) Synthesis of ZnL1

L1 was suspended in $10 \mathrm{~mL}$ of acetonitrile and a suspension of $340 \mathrm{mg}(1.426 \mathrm{mmol})$ of $\mathrm{Zn}\left(\mathrm{BF}_{4}\right)_{2} \times \mathrm{nH}_{2} \mathrm{O}$ in $5 \mathrm{~mL}$ of acetonitrile was added. The suspension was stirred at room temperature for $24 \mathrm{~h}$. The undissolved solids were then removed via filtration to obtain a yellow solution of $\mathbf{Z n L 1}$. The solvent was removed under reduced pressure and the product was directly used without any further purification.

${ }^{1} \mathrm{H} \mathrm{NMR}\left(400 \mathrm{MHz},\left(\mathrm{CD}_{3}\right)_{2} \mathrm{SO}\right): \delta=9.84(\mathrm{dd}, J=8.2,1.6 \mathrm{~Hz}, 2 \mathrm{H}), 9.23(\mathrm{dd}, J=4.9,1.6 \mathrm{~Hz}, 2 \mathrm{H}), 8.87(\mathrm{~s}, 1 \mathrm{H})$, $8.69(\mathrm{~s}, 2 \mathrm{H}), 8.30(\mathrm{dd}, J=8.2,4.9 \mathrm{~Hz}, 2 \mathrm{H})$. 


\section{$3 \quad$ Structural Characterization of C1}

\subsection{NMR Spectra}

C1 was fully characterized by proton and carbon NMR-spectroscopy measurements. (Figure S3.1 and S3.3) The assignment of the proton signals was supported by ${ }^{1} \mathrm{H},{ }^{1} \mathrm{H}-\mathrm{COSY}$ experiment. (Figure S3.2)

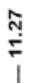
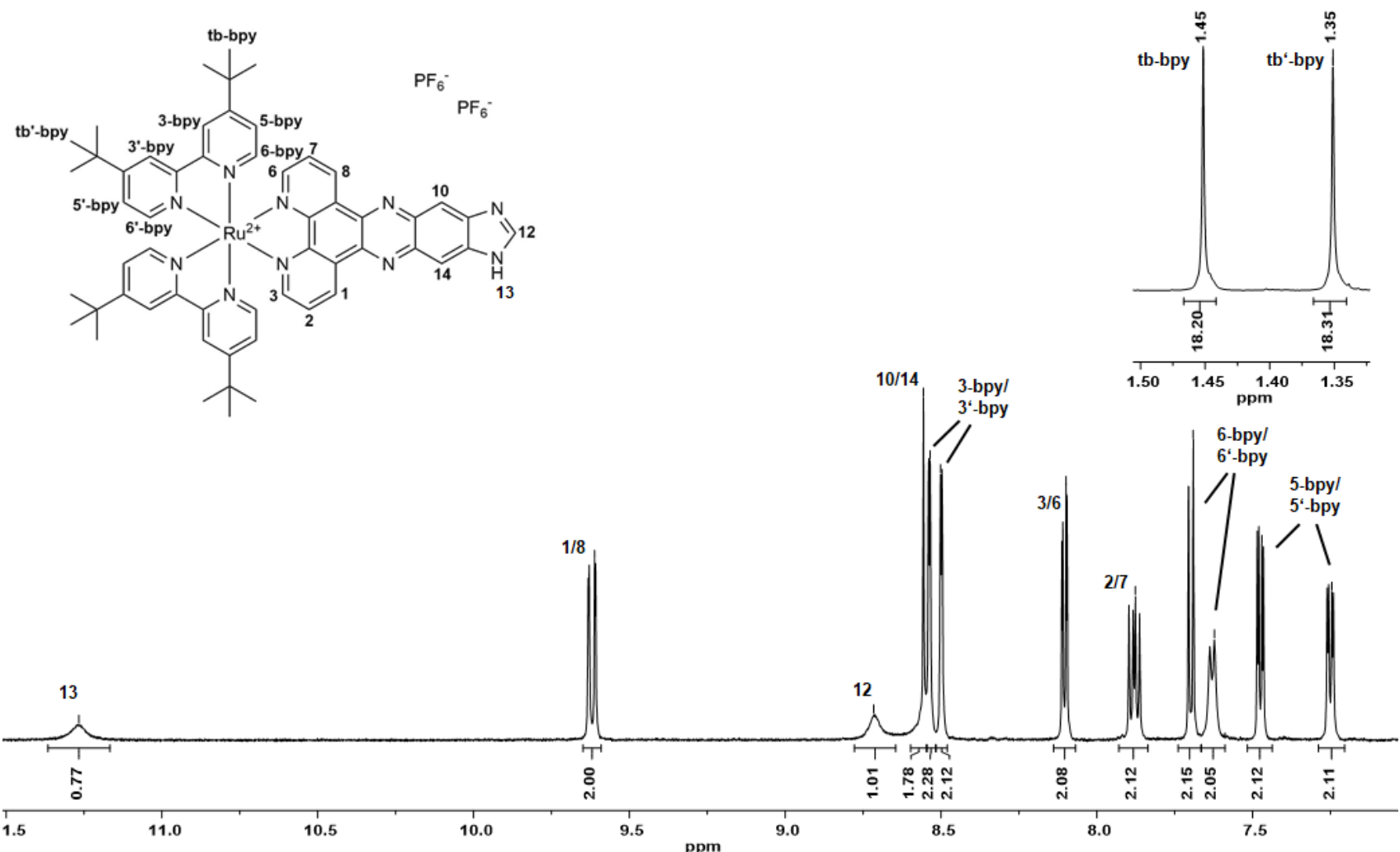

Figure S3.1. ${ }^{1} \mathrm{H}$ NMR spectrum of $\mathbf{C} 1$ in deuterated acetonitrile. 


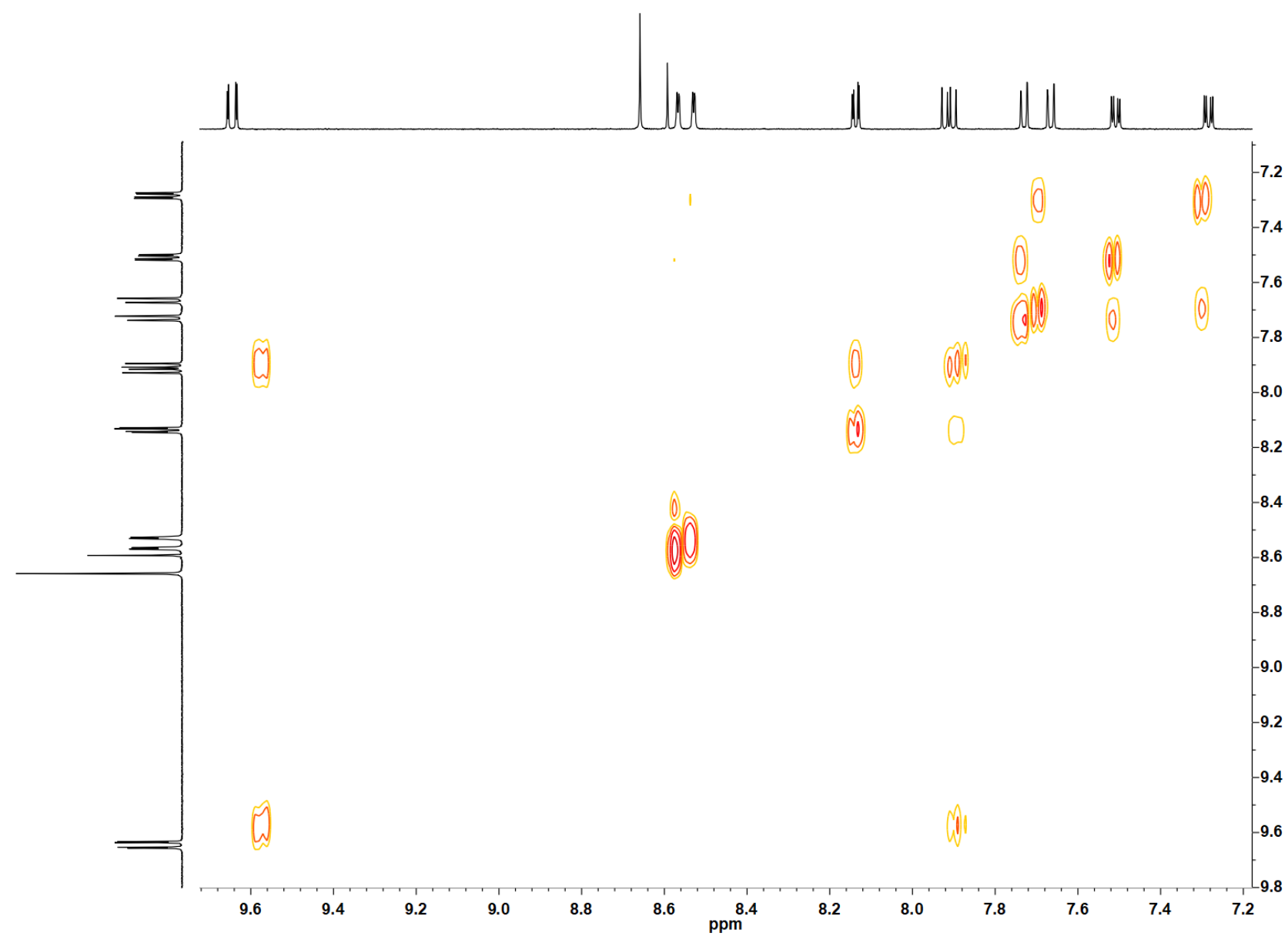

Figure S3.2. $\mathrm{H}, \mathrm{H}$ COSY spectrum of $\mathbf{C 1}$ in deuterated acetonitrile. 


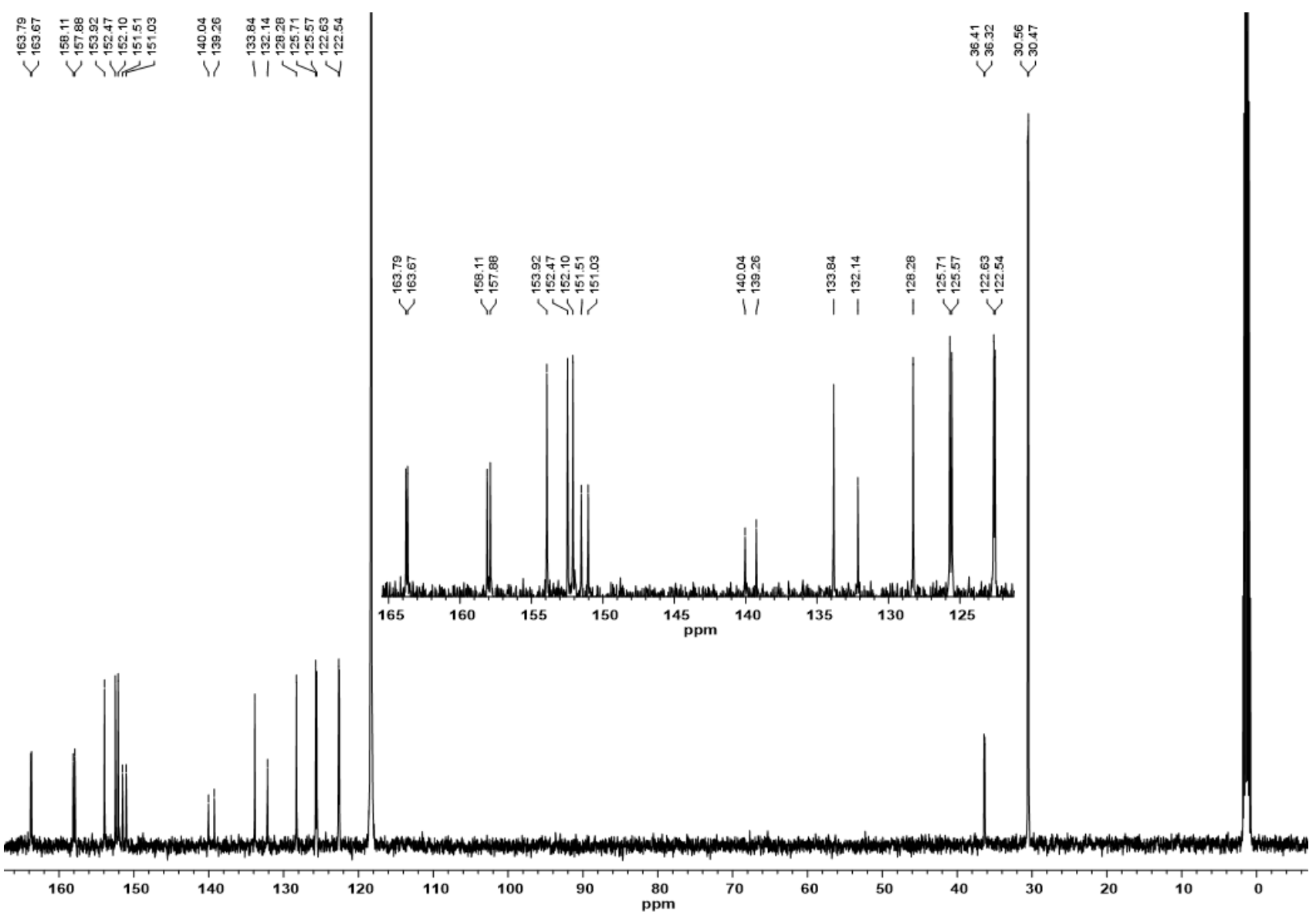

Figure S3.3. ${ }^{13} \mathrm{C}$ NMR spectrum of $\mathbf{C 1}$ in deuterated acetonitrile. 


\subsection{MS Spectra}

ESI mass spectrometry showed the formation of $\mathbf{C 1}$ with matching isotopic patterns of the detected and calculated molecular ion peaks (Figure S3.5).

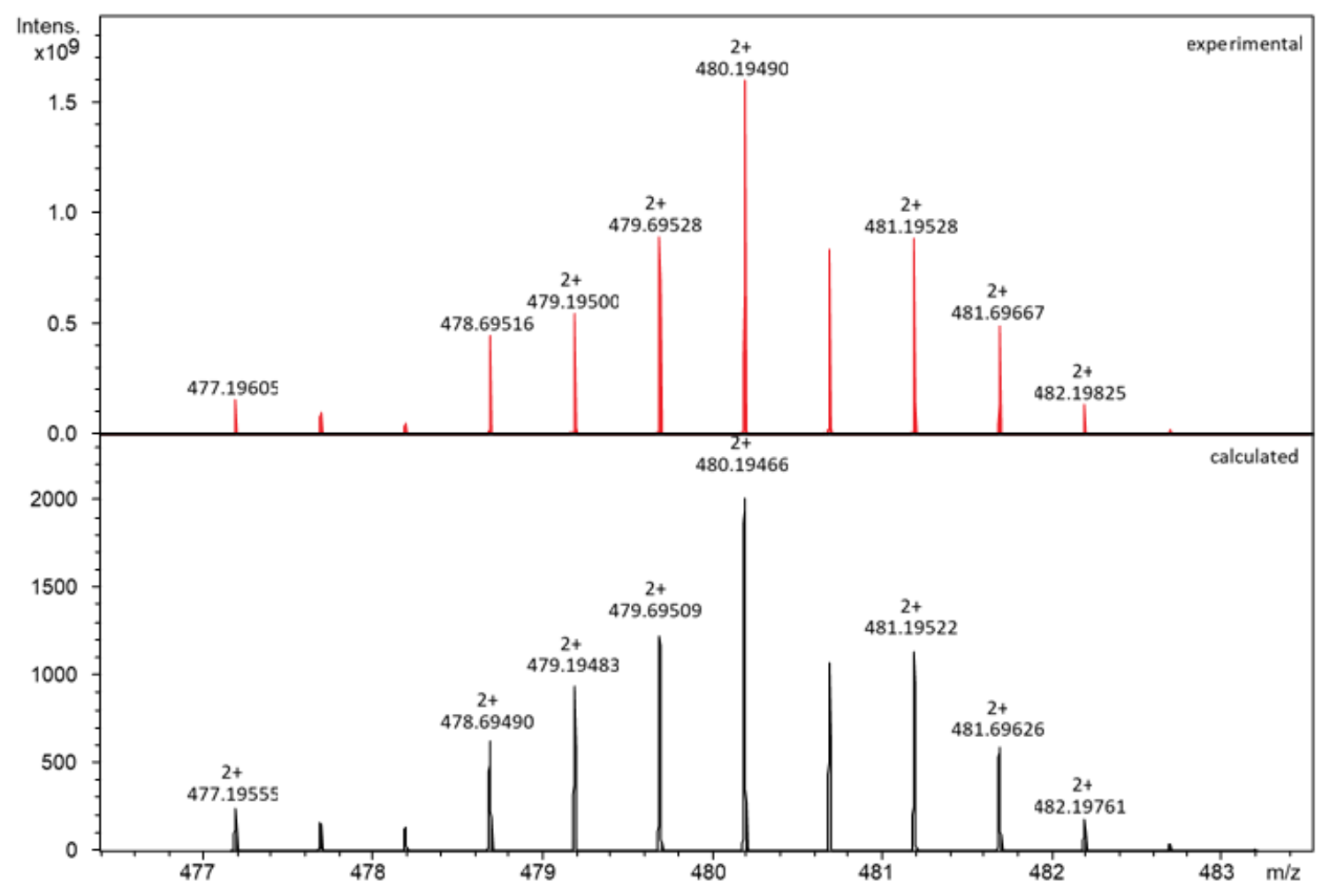

Figure S3.5. Measured (top) and calculated (bottom) ESI-MS spectrum of C1 obtained from acetonitrile solution. 


\subsection{Concentration Dependent NMR Studies}

In order to investigate the extend of $\pi-\pi$ interactions, concentration dependent proton NMRspectroscopy measurements were performed for $\mathbf{C 1}$ in acetonitrile solution. (Figure S3.4.)

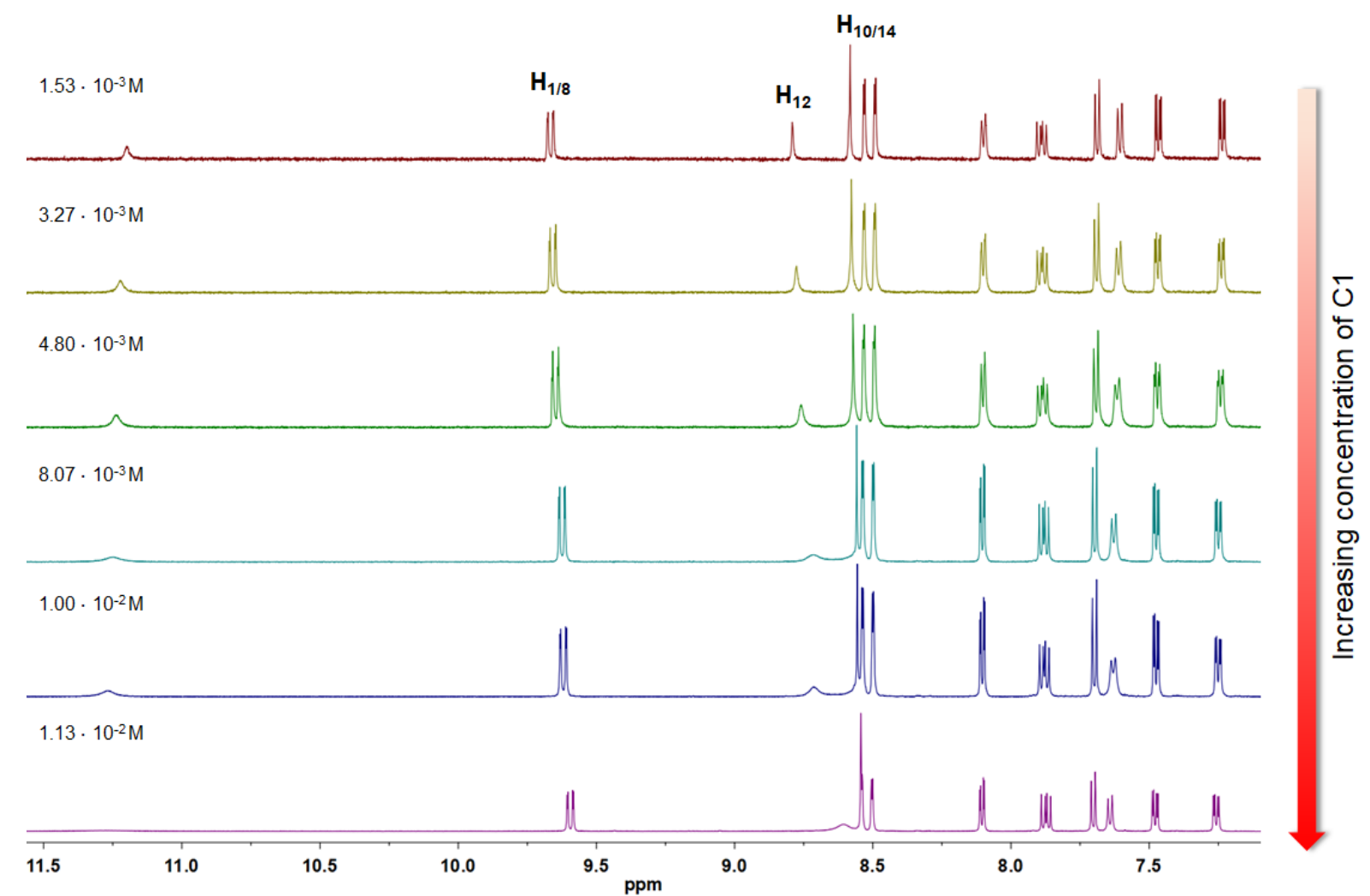

Figure S3.4. ${ }^{1} \mathrm{H}$ NMR spectra of $\mathbf{C} 1$ in deuterated acetonitrile at different concentrations from $1.53 \cdot 10^{-3}$ to $1.13 \cdot 10^{-2} \mathrm{M}$.

Upon increasing the concentration of $\mathbf{C} 1$ from $1.53 \cdot 10^{-3} \mathrm{M}$ to $1.13 \cdot 10^{-2} \mathrm{M}$, the signals for the protons in $1 / 8,10 / 14$ and 12 position shifted to lower ppm values by $0.08,0.04$ and $0.18 \mathrm{ppm}$, respectively. The chemical shift for the proton in position 13 shifts to higher ppm by $0.07 \mathrm{ppm}$. The remaining $\mathbf{L} 1$ associated chemical shifts at $8.10 \mathrm{ppm}(3 / 6)$ and $7.89 \mathrm{ppm}(2 / 7)$, as well as the chemical shifts for the 4,4'-tert-butyl-2,2'-bipyridine protons, are unaffected by changes of the concentration of $\mathbf{C 1}$. 


\subsection{UV/Vis and emission data of C1}
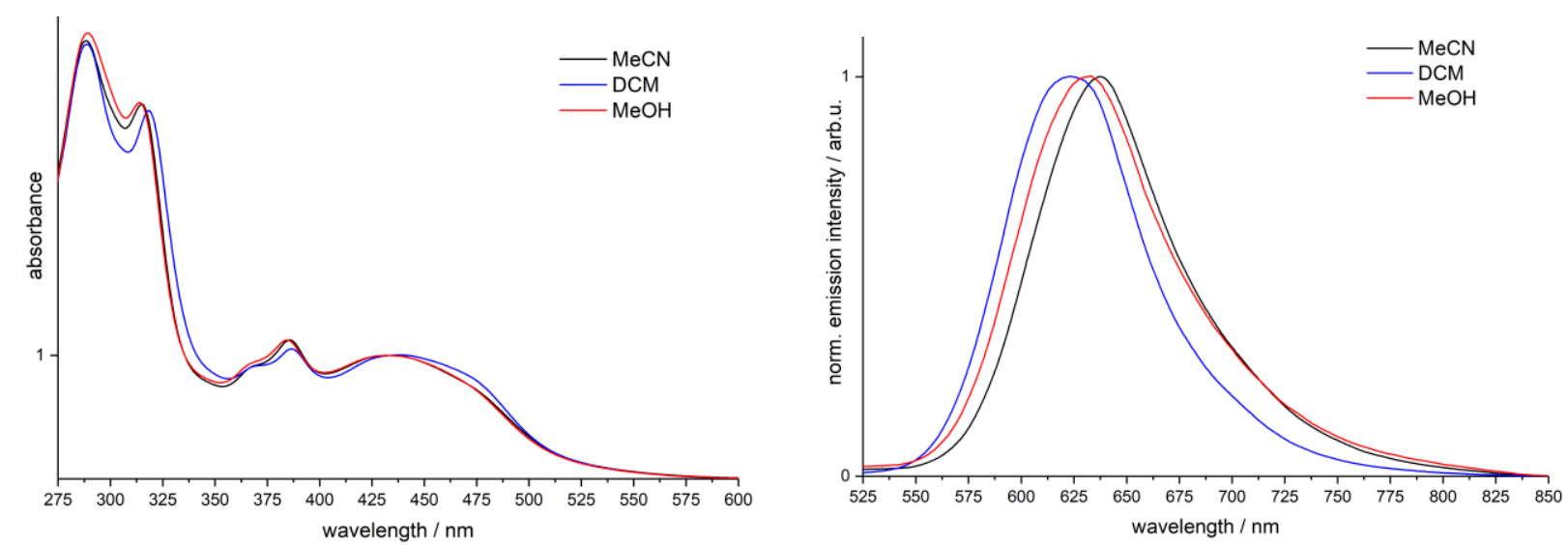

Figure S4.1. Left: UV/Vis spectra of $\mathbf{C 1}\left(\mathrm{c}=4.25 \times 10^{-5} \mathrm{M}\right)$ in acetonitrile, dichloromethane and methanol, normalized at $433 \mathrm{~nm}$. Right: Normalized emission spectra of $\mathrm{C1}\left(\mathrm{c}=4.25 \times 10^{-5} \mathrm{M}\right)$ in aerated acetonitrile, dichloromethane and methanol, recorded at an excitation wavelength of $433 \mathrm{~nm}$.

Table S4.1. Summary of the photophysical properties of $\mathbf{C 1}$ in aerated acetonitrile, dichloromethane and methanol solution.

\begin{tabular}{lccc}
\hline solvent & $\lambda_{\text {abs }}[\mathrm{nm}]\left(\varepsilon\left[\mathrm{M}^{-1} \mathrm{~cm}^{-1}\right] \cdot 10^{3}\right)$ & $\lambda_{\text {em }}[\mathrm{nm}]$ & $\Phi$ \\
\hline acetonitrile & $289(77.7), 315(63.5), 386(23.2), 433$ & 638 & $0.04^{[\mathrm{a}][\mathrm{b}]}$ \\
& $(20.9)$ & & - \\
$\begin{array}{l}\text { dichloromethane } \\
\text { methanol }\end{array}$ & $289,319,387,438$ & 623 & - \\
& $289,314,385,432$ & 633 & \\
& & \\
[a] measured in deaerated, anhydrous acetonitrile; [b] quantum yield was determined, using $\left[\mathrm{Ru}(\mathrm{bpy})_{3}\right](\mathrm{PF})_{2}$ as \\
reference.
\end{tabular}

${ }^{16}$ J. V. Caspar, T. J. Meyer, J. Am. Chem. Soc. 1983, 105, 5583-5590. 


\subsection{Photostability of CO and C1}

The stability of $\mathbf{C 1}$ was investigated under irradiation with monochromatic light of $470 \mathrm{~nm}$, as well as with an Xe-arc lamp (with and without cut-off filters) (Figure S4.2). In the chosen timeframe, both compounds show high stability when irradiated with $470 \mathrm{~nm}$ LED light. Under irradiation with the Xe-arc lamp CO and C1 show significant changes in their absorption properties in neat, degassed acetonitrile solution, as well as in a degassed acetonitrile-water mixture. However, utilization of a cut off filter, omitting shorter wavelengths then $420 \mathrm{~nm}$ ensures photostability of both compounds.
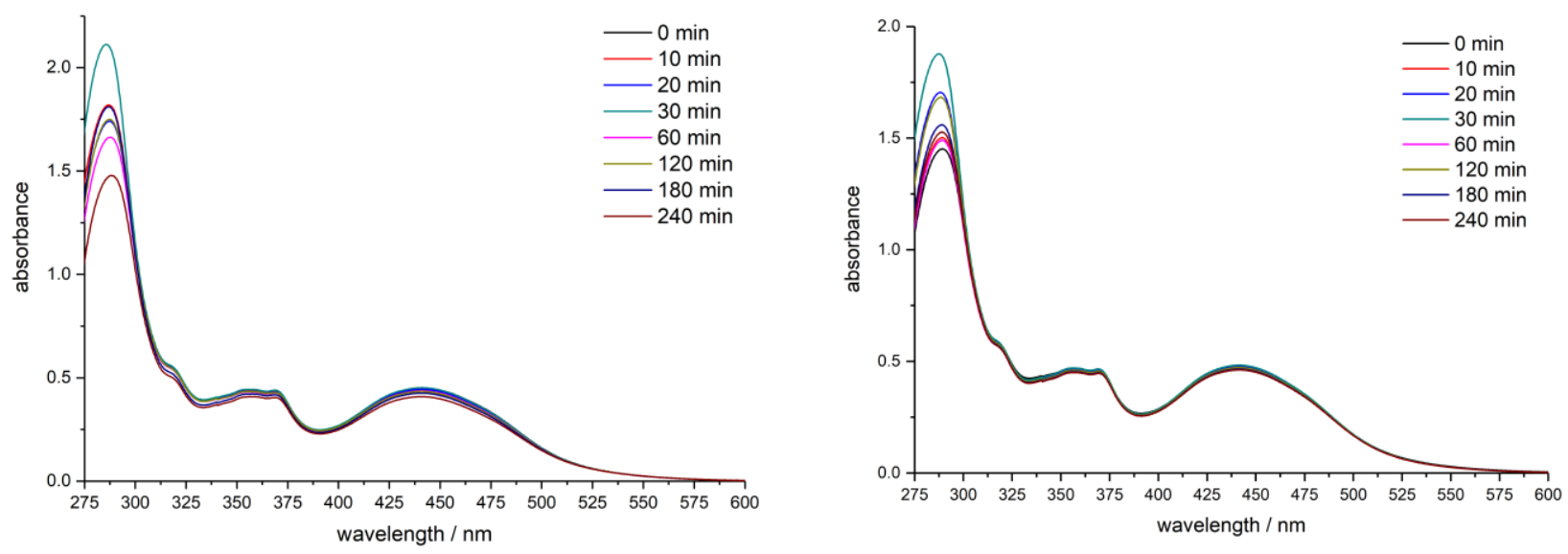

Figure S4.2. UV/Vis spectra of CO in degassed, anhydrous acetonitrile (left; $2.56 \times 10^{-5} \mathrm{M}$ ) and in a degassed acetonitrile-water mixture (v:v / 9:1) (right; $2.68 \times 10^{-5} \mathrm{M}$ ), recorded after irradiation with blue LED light $(470 \mathrm{~nm})$ for 0 to 240 minutes.
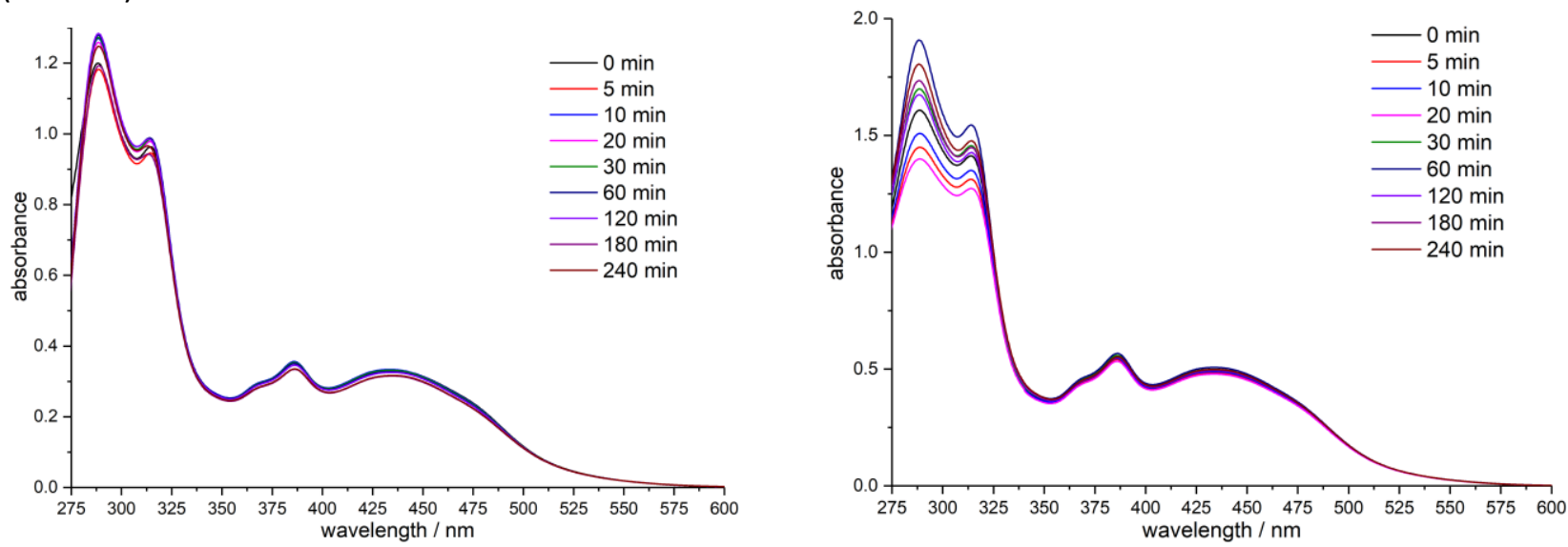

Figure S4.3. UV/Vis spectra of $\mathbf{C} 1$ in degassed, anhydrous acetonitrile (left; $1.59 \times 10^{-5} \mathrm{M}$ ) and in a deaerated acetonitrile-water mixture (v:v / 9:1) (right; $2.37 \times 10^{-5} \mathrm{M}$ ), recorded after irradiation with blue LED light (470 $\mathrm{nm}$ ) for 0 to 240 minutes. 

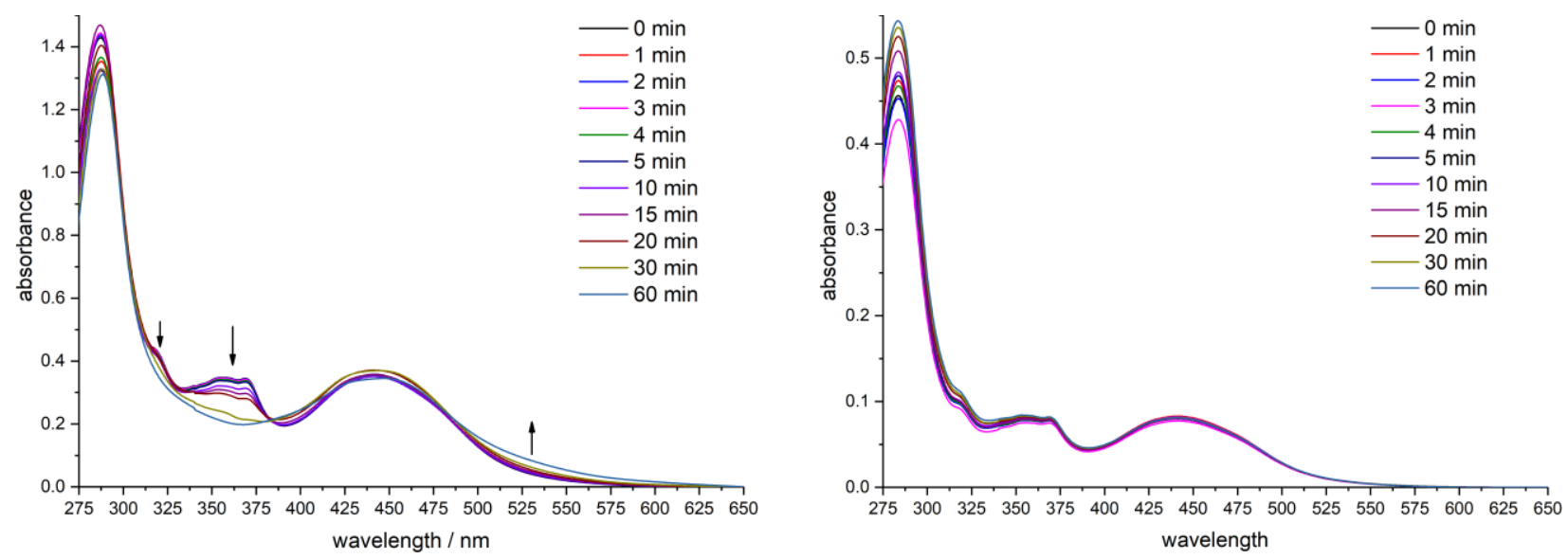

Figure S4.4. UV/vis spectra of CO in degassed, anhydrous acetonitrile, recorded after irradiation with a xenon lamp for 0 to 60 minutes (left; $2.03 \times 10^{-5} \mathrm{M}$ ). Additionally, a cut off filter was used, omitting shorter wavelengths than $420 \mathrm{~nm}$ to prevent degradation (right; $4.56 \times 10^{-6} \mathrm{M}$ ).
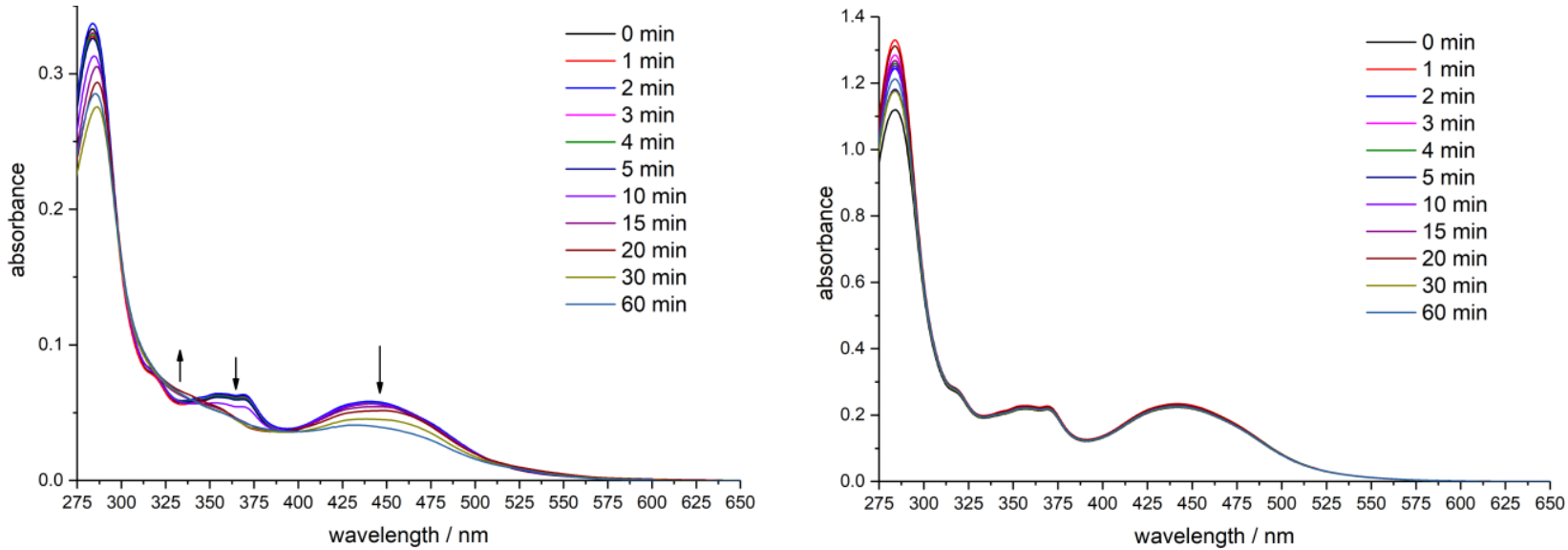

Figure S4.5. UV/vis spectra of $\mathbf{C O}$ in a degassed acetonitrile-water mixture (v:v / 9:1), recorded after irradiation with a xenon lamp for 0 to 60 minutes (left; $3.26 \times 10^{-6} \mathrm{M}$ ). Additionally, a cut off filter was used, omitting shorter wavelengths than $420 \mathrm{~nm}$ to prevent degradation (right; $1.27 \times 10^{-5} \mathrm{M}$ ).
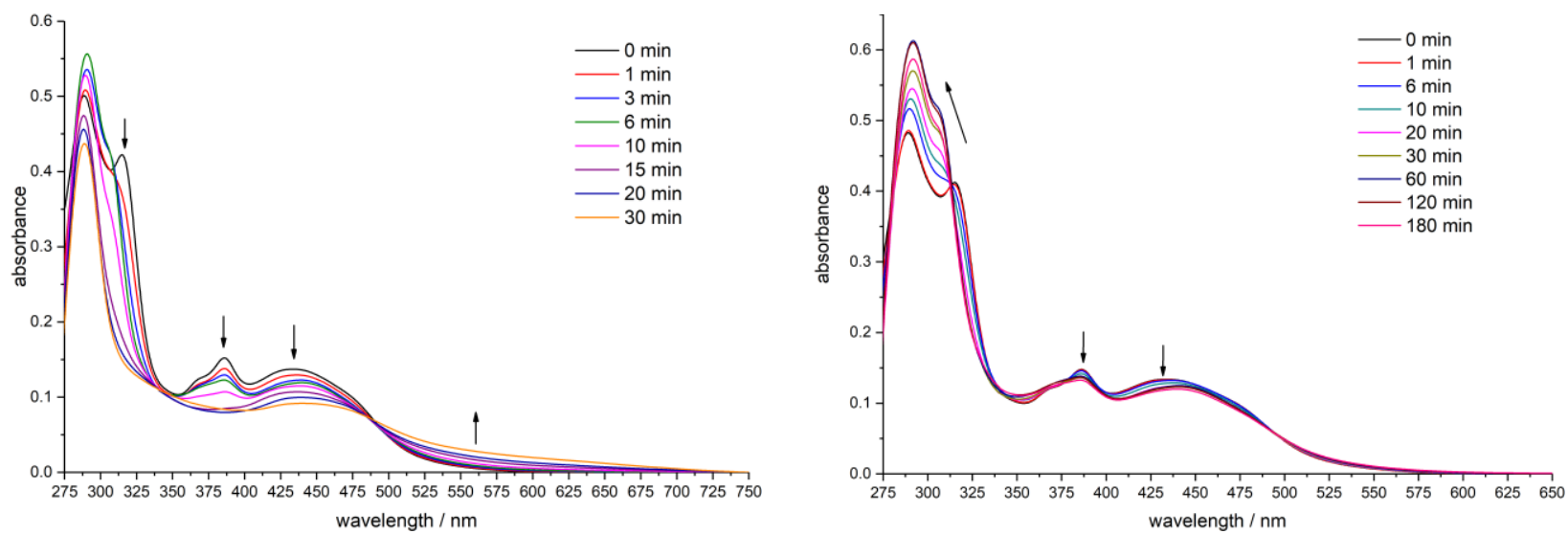

Figure S4.6. UV/vis spectra of C1 in degassed, anhydrous acetonitrile, recorded after irradiation with a xenon lamp for 0 to 60 minutes (left; $6.56 \times 10^{-6} \mathrm{M}$ ). Additionally, a cut off filter was used, omitting shorter wavelengths than $420 \mathrm{~nm}$ to prevent degradation (right; $6.39 \times 10^{-6} \mathrm{M}$ ). 

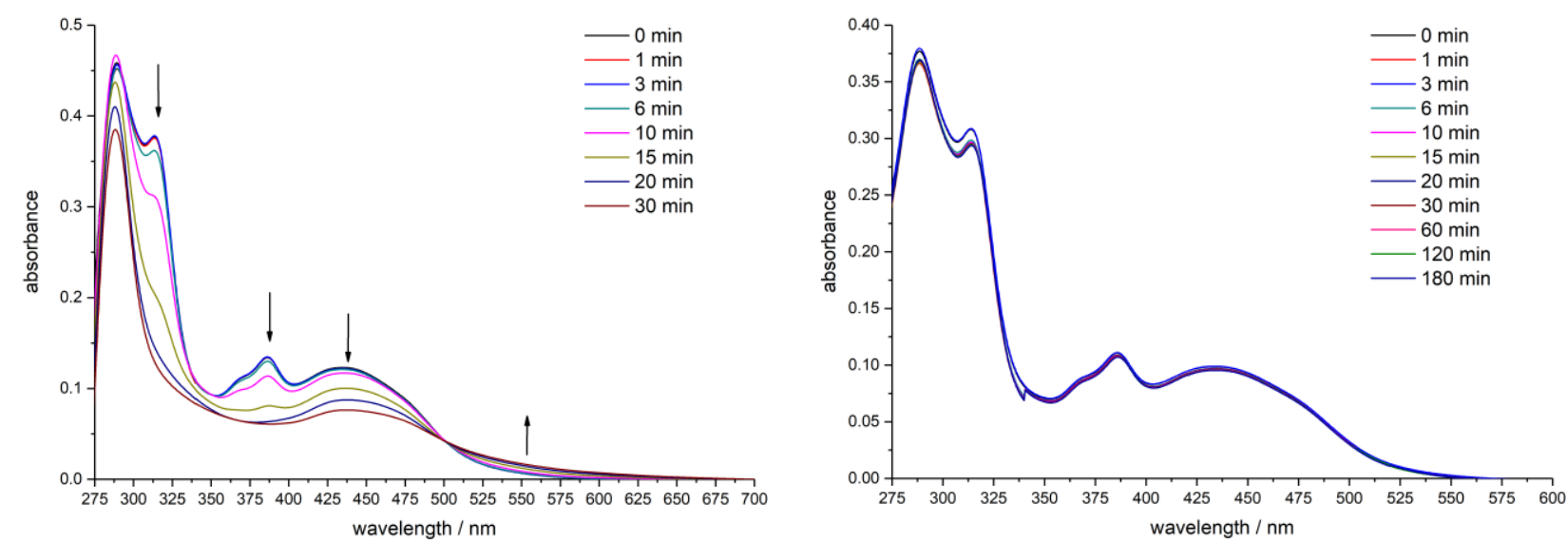

Figure S4.7. UV/vis spectra of $\mathbf{C} 1$ in a degassed acetonitrile-water mixture (v:v / 9:1), recorded after irradiation with a xenon lamp for 0 to 60 minutes (left; $5.88 \times 10^{-6} \mathrm{M}$ ). Additionally, a cut off filter was used, omitting shorter wavelengths than $420 \mathrm{~nm}$ to prevent degradation (right; $4.73 \times 10^{-6} \mathrm{M}$ ).
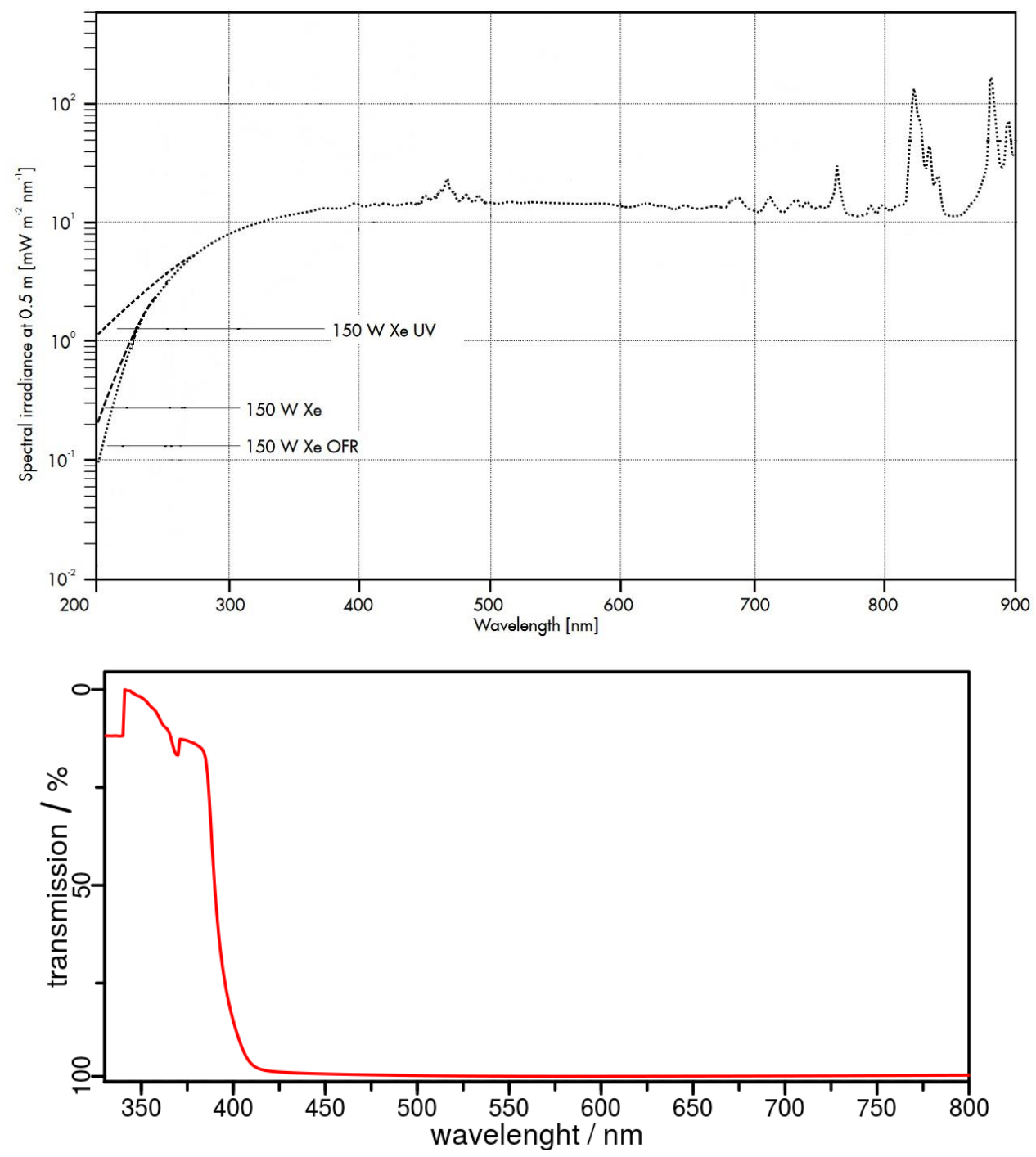

Figure S4.8. Emission spectrum of the used $150 \mathrm{~W}$ xenon arc lamp from LOT Quantum Design (top) and transmission spectrum of the used cut-off filter (bottom). 


\subsection{Luminescence quenching studies}

Water quenching studies were carried out under argon atmosphere using Schlenk techniques. Stock solutions of $\mathbf{C O}$ and $\mathbf{C 1}$ were freshly prepared in degassed, anhydrous acetonitrile with initial concentrations of $3.69 \times 10^{-6} \mathrm{M}$ and $3.76 \times 10^{-6} \mathrm{M}$, respectively. Degassed water was stepwise added and the emission spectrum was recorded at excitation wavelengths of 441 and $433 \mathrm{~nm}$ for C0 and C1, respectively. To exclude any influences of the slightly altering concentration of the solutions, absorption spectra were recorded as well and the emission spectra were normalized to the absorbance of the respective excitation wavelength.
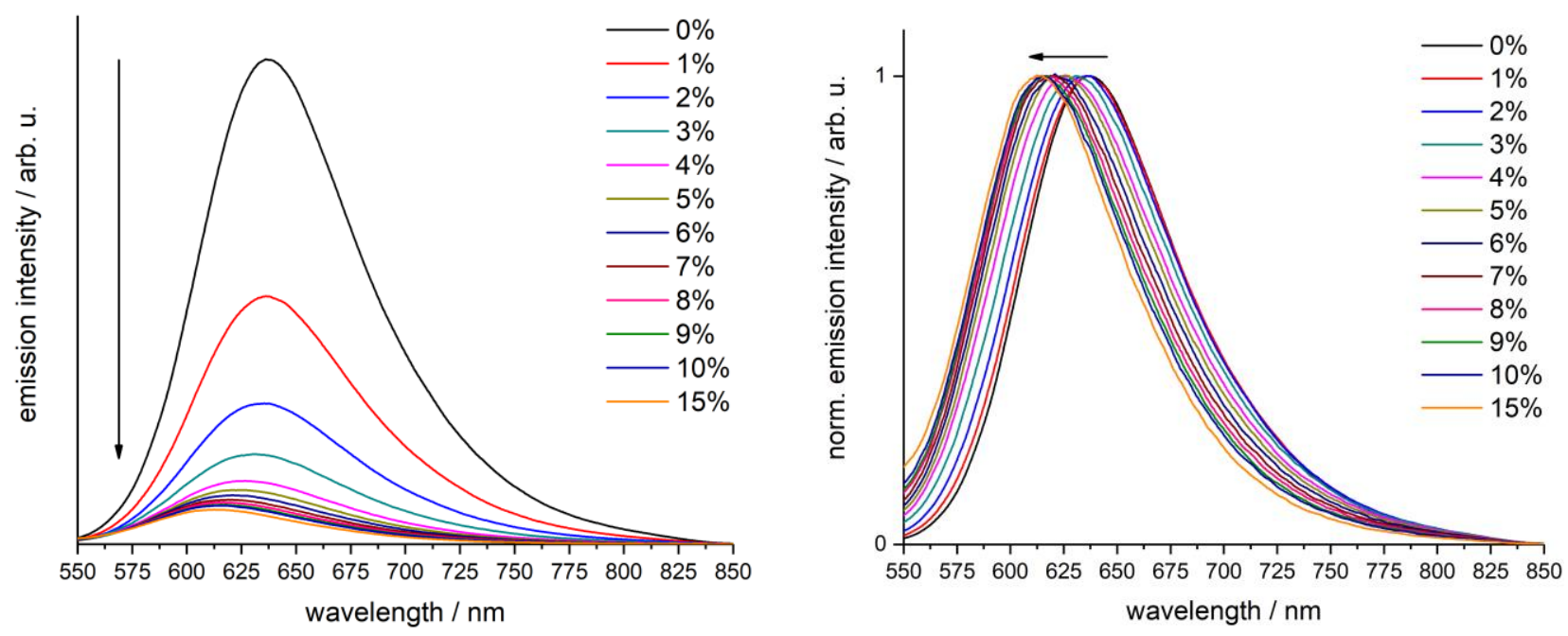

Figure S4.9. Emission spectra of $\mathbf{C O}$ in deaerated acetonitrile solution with different concentrations of water, recorded at an excitation wavelength of $441 \mathrm{~nm}$. Left: All spectra are normalized to the absorbance at the excitation wavelength. Right: All spectra are normalized to the respective emission maximum intensity.
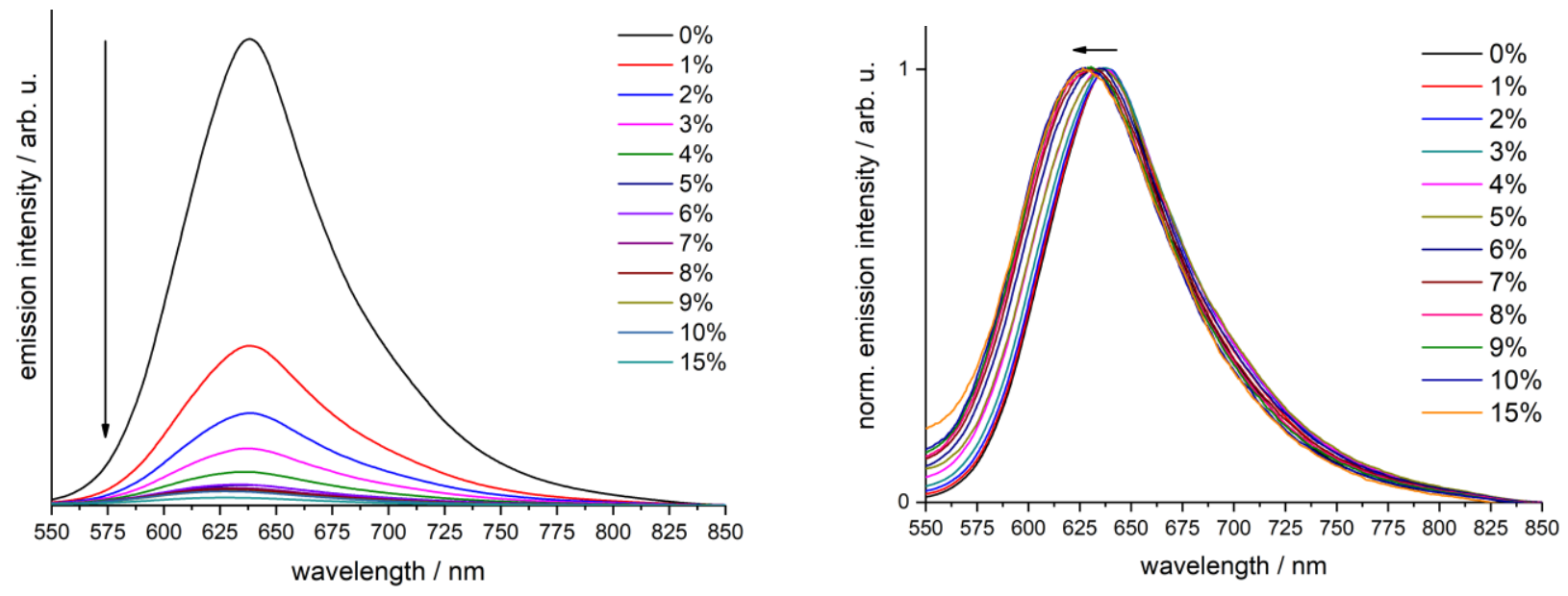

Figure S4.10. Emission spectra of $\mathbf{C 1}$ in deaerated acetonitrile solution with different concentrations of water, recorded at an excitation wavelength of $433 \mathrm{~nm}$. Left: All spectra are normalized to the absorbance 
at the excitation wavelength. Right: All spectra are normalized to the respective emission maximum intensity.

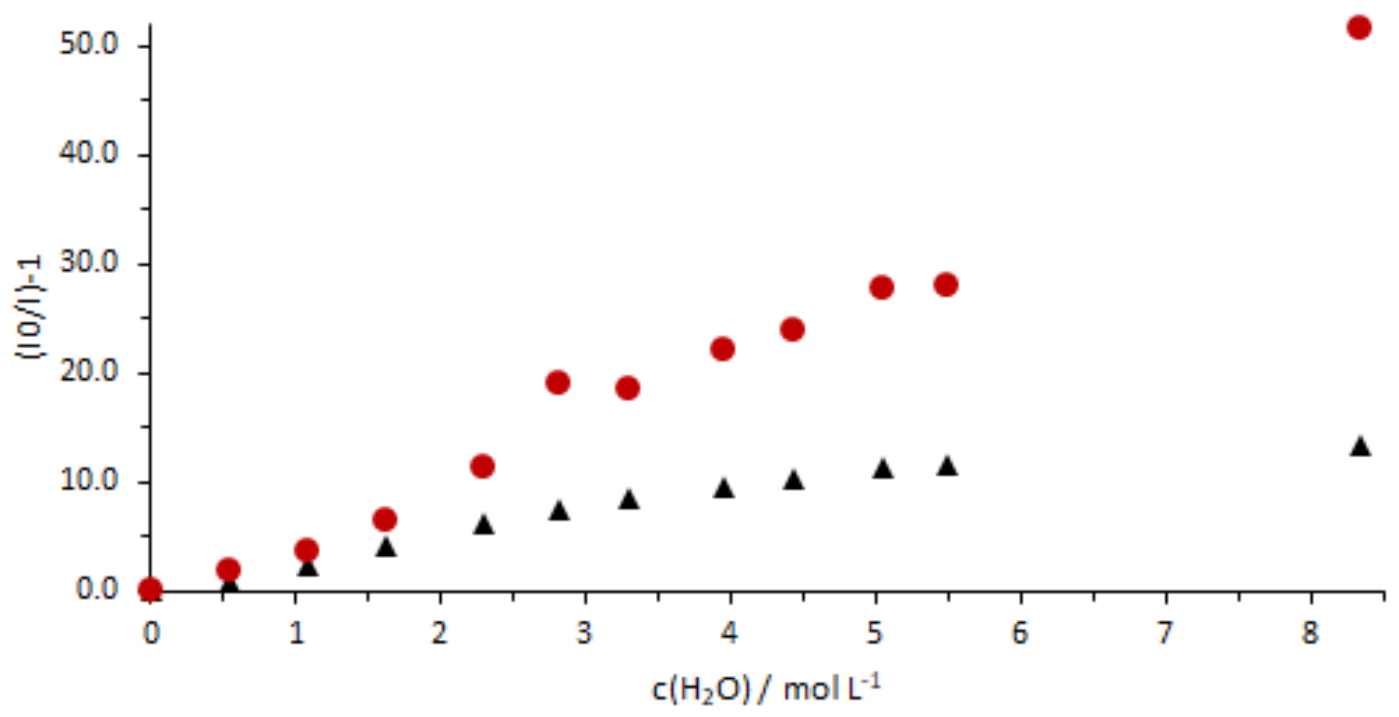

Figure S4.11. Stern Volmer Plots for the titration with water of acetonitrile solutions of CO (black triangles) and $\mathbf{C 1}$ (red dots). 


\section{$5 \quad$ Calculated Ground State Structures of C1}

The optimized ground state structure of $\mathbf{C 1}$ was calculated based on density functional theory (DFT) with a conductor-like polarizable continuum solvent correction based on acetonitrile (Figure S5.1, Table S5.1). The calculated Ru-N bond lengths of about $207 \mathrm{pm}$ and the $\mathrm{N}-\mathrm{Ru}-\mathrm{N}$ angles with approx. $78.5^{\circ}$ have typical values for ruthenium complexes with an L0 or L1 scaffold. ${ }^{17-17}$

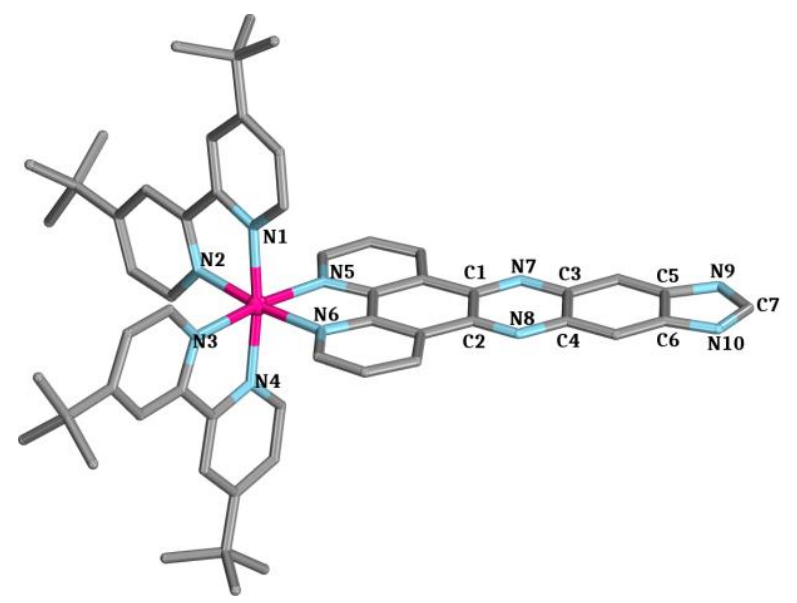

Figure S5.1. Calculated ground state $\left(\mathrm{S}_{0}\right)$ structure of $\mathbf{C 1}$ optimized at the BP86/def2-TZVP level of theory. Hydrogen atoms are omitted for clarity.

Table S5.1. Selected bond lengths $(\mathrm{pm})$ and angles $\left({ }^{\circ}\right)$ of the calculated ground state $\left(\mathrm{S}_{0}\right)$ structure BP86/def2-TZVP) of C1 in acetonitrile. For atom labeling see structures in Figure S5.1.

\begin{tabular}{|l|c|c|c|c|c|}
\hline & S $_{0}$ of 1 & & S $_{0}$ of C1 & & S of C1 \\
\hline Ru-N1 & 207 & N1-N2 & 261 & C1-N7 & 133 \\
\hline Ru-N2 & 206 & N3-N4 & 261 & C3-N7 & 136 \\
\hline Ru-N3 & 206 & N5-N6 & 264 & C2-N8 & 133 \\
\hline Ru-N4 & 207 & N7-N8 & 283 & C4-N8 & 136 \\
\hline Ru-N5 & 207 & N9-N10 & 226 & C5-N9 & 138 \\
\hline Ru-N6 & 207 & C1-C2 & 144 & C7-N9 & 137 \\
\hline N1-Ru-N2 & 78.5 & C3-C4 & 146 & C6-N10 & 139 \\
\hline N3-Ru-N4 & 78.5 & C5-C6 & 145 & C7-N10 & 132 \\
\hline N5-Ru-N6 & 79.3 & & & & \\
\hline
\end{tabular}

17 M. Atsumi, L. González, C. Daniel, J. Photochem. Photobiol. A Chem. 2007, 190, 310-320.

18 C. Kuhnt, S. Tschierlei, M. Karnahl, S. Rau, B. Dietzek, M. Schmitt, J. Popp, J. Raman Spectrosc. 2010, 41, 922932.

19 X. Gao, S. Shi, J.-L. Yao, J. Zhao, T.-M. Yao, Dalton Trans. 2015, 44, 19264-19274. 
Table S6.1. Calculated excitation energies and transition moments of complex $\mathbf{C 1}$ at full TD-DFT level (B3LYP-D3(BJ)/def2-TZVP). Only excitation with an oscillator strength $>0.01$ and corresponding orbital contributions with $\mid$ coeff. $\left.\right|^{2} \geq 0.2$ are listed. Compare with the differential densities in Figure 3 and the orbital pictures in Figure S6.1. In grey color the $\pi-\pi^{*}$ transitions are highlighted.

\begin{tabular}{|c|c|c|c|c|c|c|c|}
\hline \multirow{2}{*}{$\begin{array}{c}\text { Excitation } \\
\#\end{array}$} & \multicolumn{2}{|c|}{$\begin{array}{c}\text { Excitation } \\
\text { energy }\end{array}$} & \multirow{2}{*}{\begin{tabular}{|c|}
$\begin{array}{c}\text { Oscillator } \\
\text { strength }\end{array}$ \\
length \\
representa \\
tion
\end{tabular}} & \multicolumn{3}{|c|}{ Dominant contributions } & \multirow[t]{2}{*}{ Transitions } \\
\hline & $\mathrm{cm}^{-1}$ & $\mathrm{Nm}$ & & occ. orbital & virt. orbital & $\begin{array}{c}\mid \text { coeff. }^{2 * 1} \\
00\end{array}$ & \\
\hline 7 & 20733.0 & 482.3 & 0.1117 & HOMO-3 & LUMO & 0.4361 & $\mathrm{~d}_{\mathrm{Ru}} \rightarrow \pi^{*}{ }_{\mathrm{bpy}}$ \\
\hline \multirow[t]{2}{*}{8} & 22327.8 & 447.9 & 0.1277 & HOMO-3 & LUMO+1 & 0.4209 & $\mathrm{~d}_{\mathrm{Ru}} \rightarrow \pi^{*}{ }_{\mathrm{bpy}}$ \\
\hline & & & & HOMO-2 & LUMO+1 & 0.2207 & $\mathrm{~d}_{\mathrm{Ru}} \rightarrow \pi^{*}{ }_{\mathrm{bpy}}$ \\
\hline 9 & 23054.2 & 433.8 & 0.0154 & HOMO & LUMO+2 & 0.8968 & $\pi$ benzimidazol $\rightarrow \pi_{\text {pyrazine-benzimidazol }}$ \\
\hline 13 & 25155.0 & 397.5 & 0.0294 & HOMO-1 & LUMO+3 & 0.2987 & $\mathrm{~d}_{\mathrm{Ru}} \rightarrow \pi_{\mathrm{phen}} / \pi_{\mathrm{bpy}}$ \\
\hline 14 & 23202.7 & 431.0 & 0.0102 & HOMO & LUMO+3 & 0.7393 & $\pi_{\text {benzimidazol }} \rightarrow \pi_{\text {phen }}^{*} / \pi_{\text {bpy }}$ \\
\hline 15 & 25486.1 & 392.4 & 0.0140 & HOMO-2 & LUMO+2 & 0.4255 & $\mathrm{~d}_{\mathrm{Ru}} \rightarrow \pi_{\text {pyrazine-benzimidazol }}$ \\
\hline 19 & 26238.3 & 381.1 & 0.0372 & HOMO-3 & LUMO+2 & 0.3676 & $\mathrm{~d}_{\mathrm{Ru}} \rightarrow \pi_{\text {pyrazine-benzimidazol }}$ \\
\hline 24 & 25281.1 & 395.6 & 0.0213 & HOMO & LUMO+5 & 0.6576 & $\pi_{\text {benzimidazol }} \rightarrow \pi_{\text {phen }}^{*} / \pi_{\text {bpy }}$ \\
\hline \multirow[t]{2}{*}{29} & 27923.5 & 358.1 & 0.0201 & HOMO-2 & LUMO+7 & 0.2181 & $\mathrm{~d}_{\mathrm{Ru}} \rightarrow \pi^{*}{ }_{\mathrm{bpy}}$ \\
\hline & & & & HOMO & LUMO+6 & 0.2972 & $\pi_{\text {benzimidazol }} \rightarrow \pi_{\text {bpy }}$ \\
\hline 30 & 28179.6 & 354.9 & 0.0409 & HOMO-1 & LUMO+7 & 0.2375 & $\mathrm{~d}_{\mathrm{Ru}} \rightarrow \pi_{\mathrm{bpy}}$ \\
\hline 33 & 28386.0 & 352.3 & 0.0159 & HOMO-1 & LUMO+7 & 0.2056 & $\mathrm{~d}_{\mathrm{Ru}} \rightarrow \pi^{*}{ }_{\mathrm{bpy}}$ \\
\hline \multirow[t]{2}{*}{34} & 28484.2 & 351.1 & 0.0236 & HOMO-4 & LUMO+2 & 0.2209 & $\mathrm{~d}_{\mathrm{Ru}} \rightarrow \pi_{\text {pyrazine-benzimidazol }}$ \\
\hline & & & 0.0236 & HOMO & LUMO+7 & 0.3365 & $\pi_{\text {benzimidazol }} \rightarrow \pi_{\text {bpy }}$ \\
\hline 35 & 27393.4 & 365.1 & 0.0201 & HOMO & LUMO+7 & 0.6157 & $\pi_{\text {benzimidazol }} \rightarrow \pi^{*}{ }_{\text {bpy }}$ \\
\hline 36 & 28694.3 & 348.5 & 0.0528 & HOMO-2 & LUMO+6 & 0.3743 & $\mathrm{~d}_{\mathrm{Ru}} \rightarrow \pi_{\mathrm{bpy}}$ \\
\hline 38 & 29401.3 & 340.1 & 0.0811 & HOMO-3 & LUMO+6 & 0.6753 & $\mathrm{~d}_{\mathrm{Ru}} \rightarrow \pi^{*}{ }_{\mathrm{bpy}}$ \\
\hline 39 & 29636.3 & 337.4 & 0.0401 & HOMO-3 & LUMO+7 & 0.7405 & $\mathrm{~d}_{\mathrm{Ru}} \rightarrow \pi^{*}{ }_{\mathrm{bpy}}$ \\
\hline 40 & 28591.3 & 349.8 & 0.0384 & HOMO-4 & LUMO+3 & 0.6042 & $d_{R u} \rightarrow \pi^{*}$ phen $/ \pi^{*}{ }_{\text {bpy }}$ \\
\hline 41 & 30093.8 & 332.3 & 0.1733 & HOMO-4 & LUMO+4 & 0.3292 & $\mathrm{~d}_{\mathrm{Ru}} \rightarrow \pi^{*}$ phen \\
\hline 42 & 30466.6 & 328.2 & 0.0820 & HOMO-1 & LUMO+8 & 0.4452 & $d_{\mathrm{Ru}} \rightarrow \pi^{*}{ }_{\text {phen }}$ \\
\hline 43 & 31105.6 & 321.5 & 0.0843 & HOMO-3 & LUMO+8 & 0.2760 & $\mathrm{~d}_{\mathrm{Ru}} \rightarrow \pi^{*}{ }_{\text {phen }}$ \\
\hline \multirow[t]{2}{*}{45} & 31544.2 & 317.0 & 0.0112 & HOMO-3 & LUMO+8 & 0.2739 & $d_{\mathrm{Ru}} \rightarrow \pi^{*}$ phen \\
\hline & & & 0.0112 & HOMO-2 & LUMO+8 & 0.3214 & $\mathrm{~d}_{\mathrm{Ru}} \rightarrow \pi^{*}{ }_{\text {phen }}$ \\
\hline 48 & 32570.5 & 307.0 & 0.0169 & HOMO-1 & LUMO+12 & 0.2287 & $\mathrm{~d}_{\mathrm{Ru}} \rightarrow \mathrm{d}_{\mathrm{Ru}}$ \\
\hline 49 & 32427.7 & 308.4 & 0.0266 & HOMO-4 & LUMO+6 & 0.5536 & $d_{\mathrm{Ru}} \rightarrow \pi^{*}{ }_{\mathrm{bpy}}$ \\
\hline 50 & 32531.5 & 307.4 & 0.5112 & HOMO-5 & LUMO+8 & 0.2089 & $\pi_{\text {pyrazine }} \rightarrow \pi_{\text {phen }}$ \\
\hline 53 & 32881.7 & 304.1 & 0.2360 & HOMO-4 & LUMO+7 & 0.2474 & $d_{\mathrm{Ru}} \rightarrow \pi^{*}{ }_{\mathrm{bpy}}$ \\
\hline 58 & 34180.7 & 292.6 & 0.0260 & HOMO-4 & LUMO+7 & 0.2216 & $\mathrm{~d}_{\mathrm{Ru}} \rightarrow \pi^{*}{ }_{\text {bpy }}$ \\
\hline 60 & 34684.5 & 288.3 & 0.0158 & HOMO-6 & LUMO+3 & 0.3776 & $\pi_{\text {phen }} \rightarrow \pi_{\text {phen }}^{*} / \pi^{*}{ }_{\text {bpy }}$ \\
\hline 68 & 36141.2 & 276.7 & 0.0548 & HOMO-4 & LUMO+8 & 0.3015 & $\mathrm{~d}_{\mathrm{Ru}} \rightarrow \pi^{*}{ }_{\text {phen }}$ \\
\hline 69 & 37217.4 & 268.7 & 0.0534 & HOMO-6 & LUMO+5 & 0.2586 & $\pi_{\text {phen }} \rightarrow \pi_{\text {phen }} / \pi^{*}{ }_{\text {bpy }}$ \\
\hline 70 & 37127.1 & 269.3 & 0.0189 & HOMO-6 & LUMO+6 & 0.5791 & $\pi_{\text {phen }} \rightarrow \pi_{\text {bpy }}$ \\
\hline 71 & 36830.1 & 271.5 & 0.0521 & HOMO-2 & LUMO+12 & 0.2060 & $\mathrm{~d}_{\mathrm{Ru}} \rightarrow \mathrm{d}_{\mathrm{Ru}}$ \\
\hline 72 & 37483.8 & 266.8 & 0.0223 & HOMO-10 & LUMO & 0.2627 & $\pi_{\text {phen/pyrazine/benzimidazol }} \rightarrow \pi^{*}{ }_{\text {bpy }}$ \\
\hline 73 & 37563.2 & 266.2 & 0.1439 & HOMO-10 & LUMO & 0.3816 & $\pi_{\text {phen/pyrazine/benzimidazol }} \rightarrow \pi^{*}$ bpy \\
\hline 74 & 37477.6 & 266.8 & 0.0967 & HOMO-9 & LUMO+1 & 0.2307 & $\pi_{\mathrm{bpy}} \rightarrow \pi_{\mathrm{bpy}}$ \\
\hline 78 & 37740.2 & 265.0 & 0.0761 & HOMO-6 & LUMO+7 & 0.4666 & $\pi_{\text {phen }} \rightarrow \pi *_{\text {bpy }}$ \\
\hline 79 & 38326.1 & 260.9 & 0.3614 & HOMO-10 & LUMO+1 & 0.4650 & $\pi_{\text {phen/pyrazine/benzimidazol }} \rightarrow \pi^{*}$ bpy \\
\hline 80 & 38399.6 & 260.4 & 0.0448 & HOMO-1 & LUMO+10 & 0.4061 & $d_{\mathrm{Ru}} \rightarrow \pi_{\mathrm{bpy}}$ \\
\hline
\end{tabular}




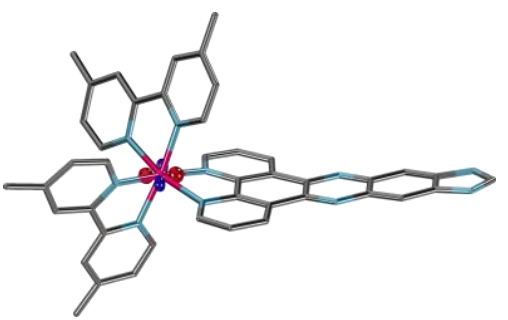

HOMO-3

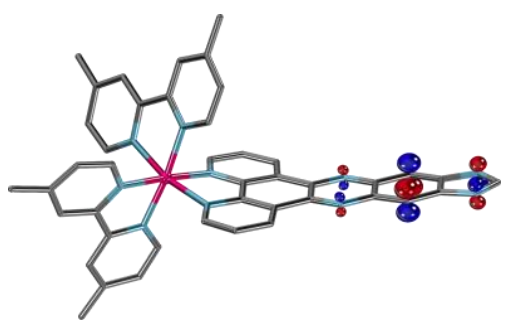

HOMO

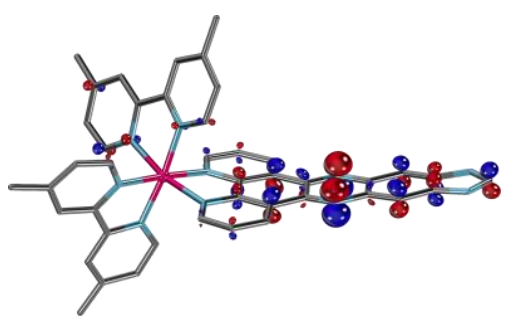

LUMO+2

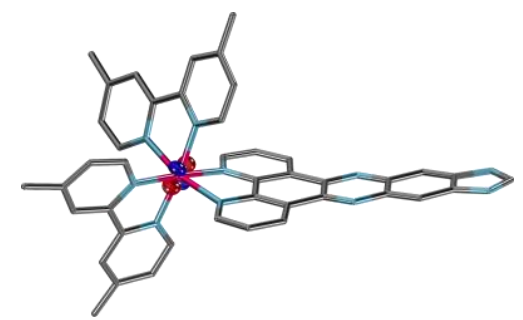

HOMO-2

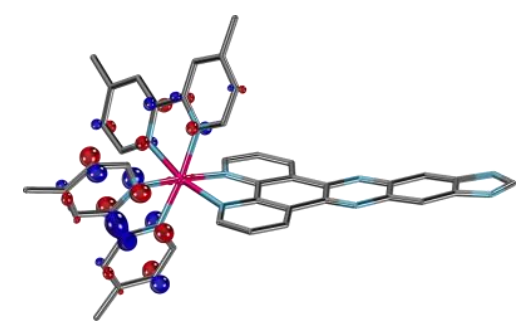

LUMO

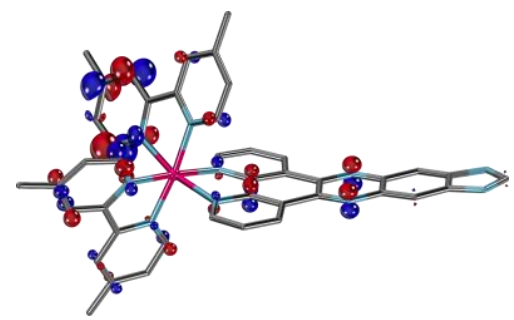

LUMO+3

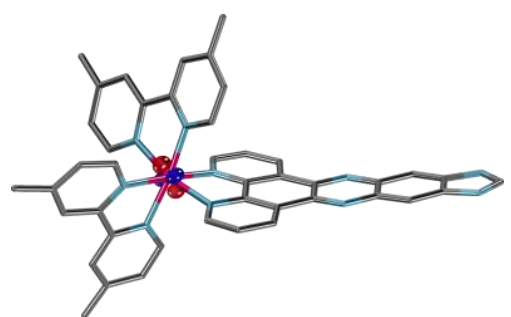

HOMO-1

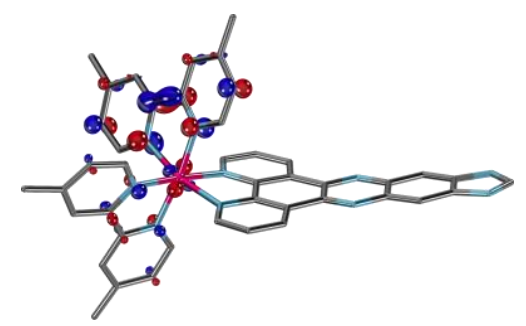

LUMO+1

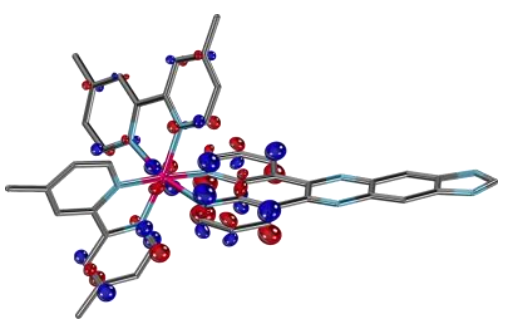

LUMO+4

Figure S6.2. Presentation of the orbitals of complex C1 at B3LYP-D3(BJ)/def2-TZVP level of theory. 


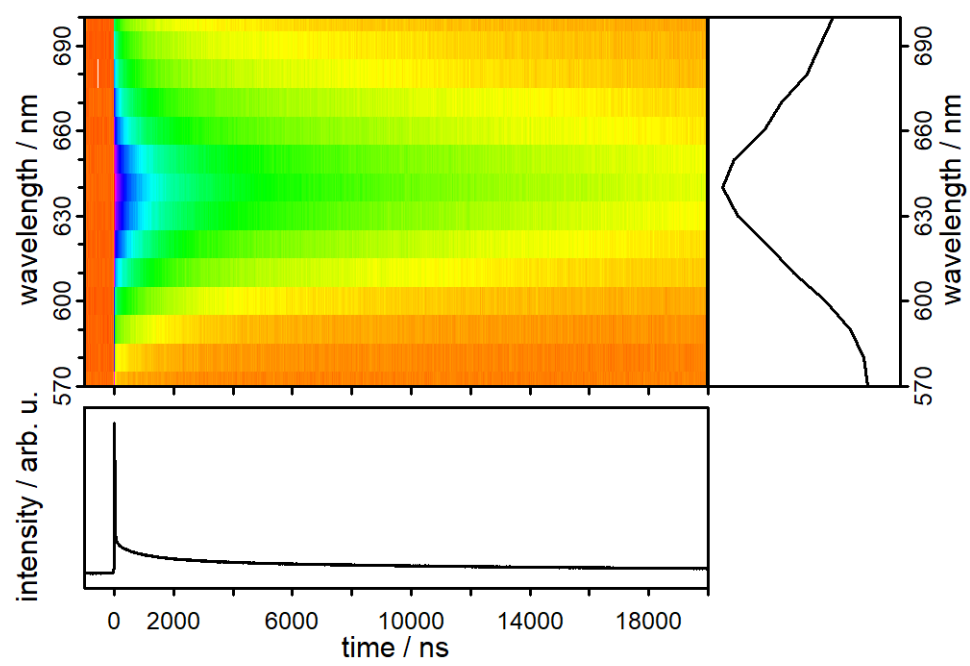

Figure S7.1. 2D Kinetic emission map of complex C1 after excitation at $355 \mathrm{~nm}$ for $\lambda_{\mathrm{em}}=570-700 \mathrm{~nm}$ in acetonitrile under inert conditions with $\tau_{1}=1.07, \tau_{2}=13.40 \mu s$. (The emission lifetimes have been determined via a global analysis with the fit function $\left.F(\lambda, t)=\sum_{i}^{2} c_{i}(\lambda) \cdot \exp \left(-t / \tau_{i}\right)+c_{0}\right)$. Please note that the lifetimes are shorter, due to a slight altering of the sample and oxygen diffusion).
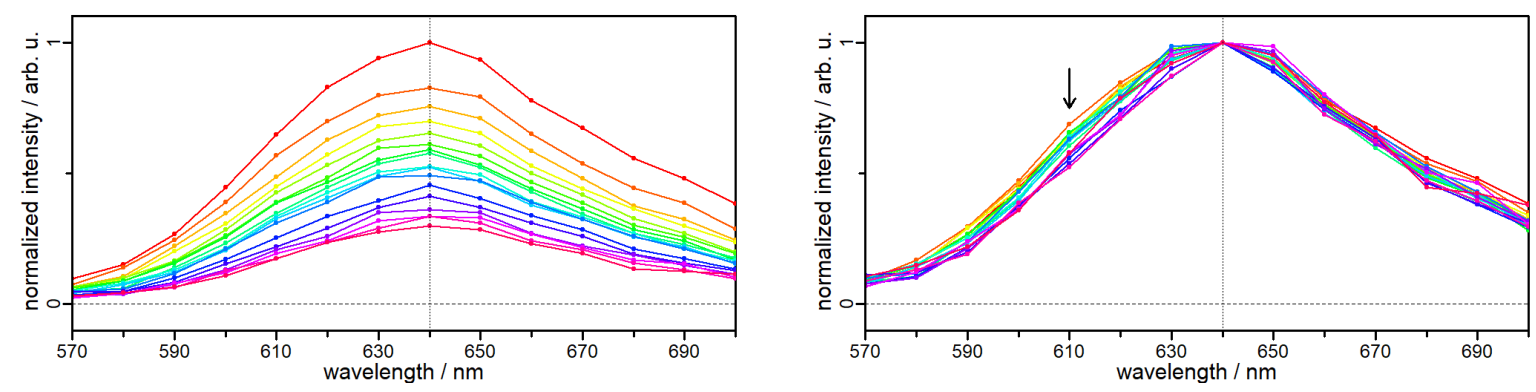

Figure S7.2. Time-resolved emission spectra (excitation at $355 \mathrm{~nm}$ ) after $\mathrm{t}=0.1$ (red) to $\mathrm{t}=8.0$ (magenta) $\mu \mathrm{s}(0.2 \mu \mathrm{s}$ increments from $0.1-2.0 \mu \mathrm{s}$ and $1.0 \mu \mathrm{s}$ increments from $2.0-8.0 \mu \mathrm{s})$. The vertical line corresponds to the emission maximum at $\mathrm{t}=0.1 \mu \mathrm{s}$.

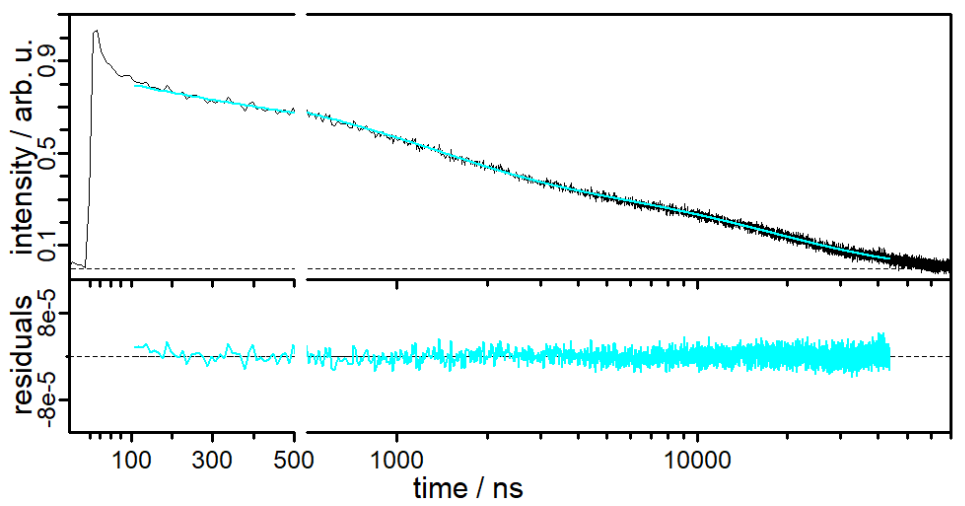

Figure S7.3. Time-resolved emission measurements at $\lambda_{\mathrm{em}}=638 \mathrm{~nm}$ of complex $\mathbf{C} \mathbf{1}$ after excitation at 355 $\mathrm{nm}$ in acetonitrile under inert conditions (black) and bi-exponential fit (cyan) with $\boldsymbol{\tau}_{\mathbf{1}}=\mathbf{1 . 1 9} \pm$ $0.01 \mu \mathrm{s}$ and $\tau_{2}=18.25 \pm 0.18 \mu \mathrm{s}$. The residuals of the fit function are given below. Compare also with Fig. 7 in the main text. The kinetic is plotted on a logarithmic scale for better clarity. 


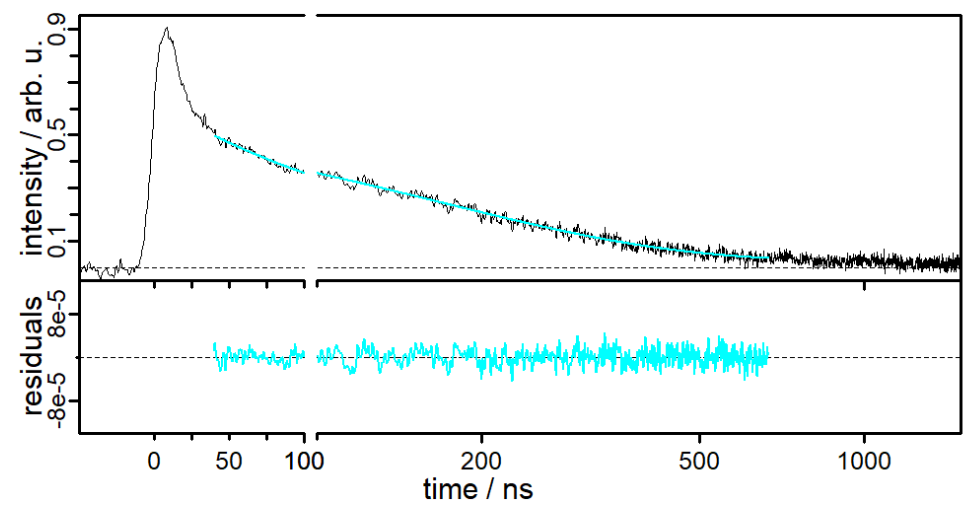

Figure S7.4. Kinetic emission measurements at $\lambda=638 \mathrm{~nm}$ of complex $\mathbf{C 1}$ after excitation at $355 \mathrm{~nm}$ in acetonitrile $/ \mathrm{H}_{2} \mathrm{O}(10 \% \mathrm{v} / \mathrm{v})$ under inert conditions (black) and mono-exponential fit (cyan) with $\boldsymbol{\tau}_{\mathbf{1}}=$ 169. $7 \pm 1.4 \mathrm{~ns}$. The kinetic is plotted on a logarithmic scale for better clarity.

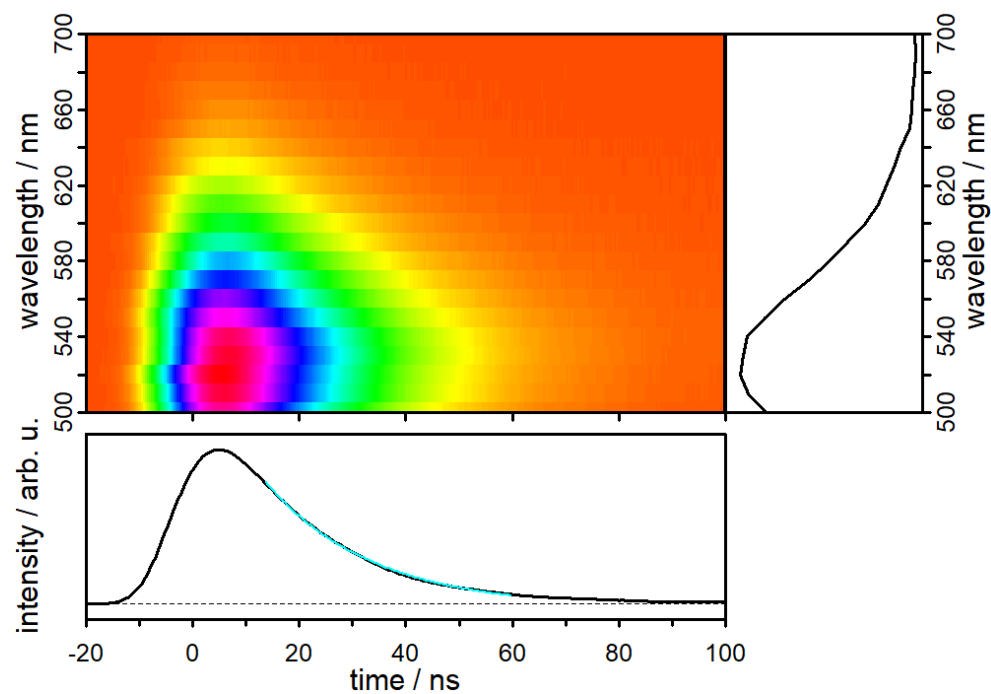

Figure S7.5. 2D Kinetic emission map of complex ZnL1 after excitation at $355 \mathrm{~nm}$ for $\lambda_{\mathrm{em}}=500-700 \mathrm{~nm}$ in acetonitrile under inert conditions. The lifetime has been determined to approximately $20 \mathrm{~ns}$ (cyan line). 


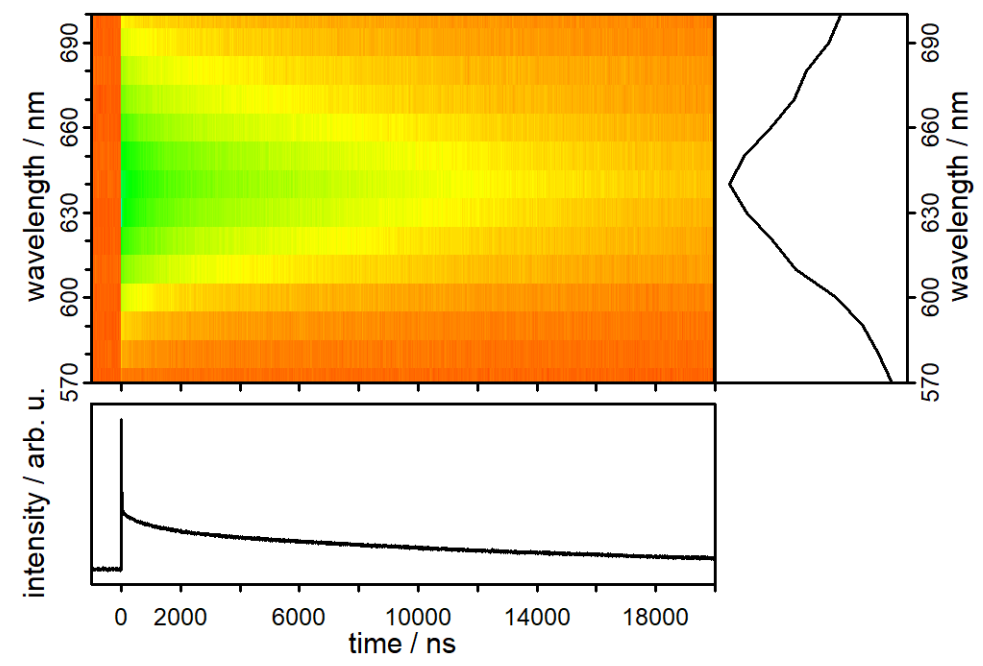

Figure S7.6. 2D Kinetic emission map of complex C1 after excitation at $532 \mathrm{~nm}$ for $\lambda_{\mathrm{em}}=570-700 \mathrm{~nm}$ in acetonitrile under inert conditions with $\tau_{\mathbf{1}}=1.05, \tau_{\mathbf{2}}=\mathbf{1 6 . 6 6} \boldsymbol{\mu s}$. (The emission lifetimes have been determined via a global analysis with the fit function $\left.F(\lambda, t)=\sum_{i}^{2} c_{i}(\lambda) \cdot \exp \left(-t / \tau_{i}\right)+c_{0}\right)$.

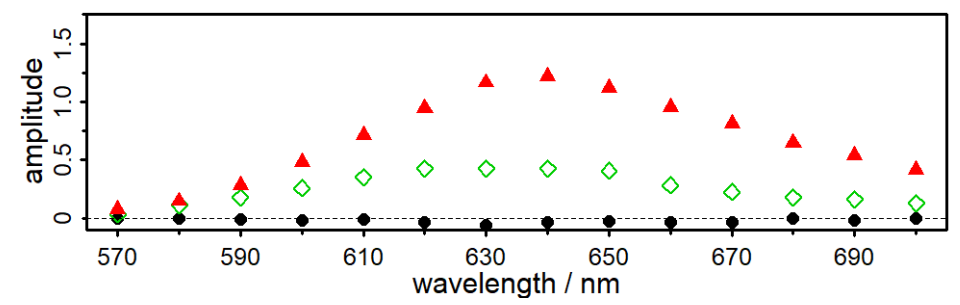

Figure S7.7. Decay-associated spectra of the bi-exponential fit with of complex $\mathbf{C 1}$ after excitation at 532 $\mathrm{nm}$ for $\lambda_{\mathrm{em}}=570-700 \mathrm{~nm}$ in acetonitrile under inert conditions with $\boldsymbol{\tau}_{\mathbf{1}}=\mathbf{1 . 0 5}, \boldsymbol{\tau}_{\mathbf{2}}=\mathbf{1 6 . 6 6} \boldsymbol{\mu s}$.

(compare with Figure S7.6). The amplitudes of the fit function $\left.F(\lambda, t)=\sum_{i}^{2} c_{i}(\lambda) \cdot \exp \left(-t / \tau_{i}\right)+c_{0}\right)$ are displayed in green squares $\left(c_{1}\right)$, red triangles $\left(c_{2}\right)$ and in black dots ( $c_{0}$, long-living component).

Please note, that a different solvent batch was used for this measurement. Reproduction of the measurement with excitation wavelength $\lambda=355 \mathrm{~nm}$ under the same conditions yields $\boldsymbol{\tau}_{\mathbf{1}}=\mathbf{1 . 1 0} \boldsymbol{\mu} \mathbf{S}$ and $\tau_{2}=14.66 \mu$ s with comparable amplitudes.

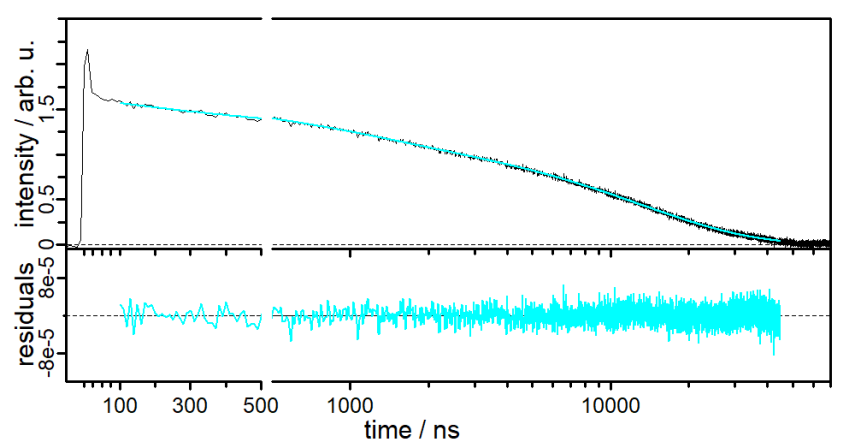

Figure S7.8. Time-resolved emission measurements at $\lambda_{\mathrm{em}}=637 \mathrm{~nm}$ of complex $\mathbf{C} \mathbf{1}$ after excitation at 532 $\mathrm{nm}$ in acetonitrile under inert conditions (black) and bi-exponential fit (cyan) with $\boldsymbol{\tau}_{\mathbf{1}}=\mathbf{0 . 9 1} \pm \mathbf{0 . 0 2} \boldsymbol{\mu S}$ and $\tau_{2}=13.06 \pm 0.04 \mu \mathrm{s}$. The residuals of the fit function are given below. The kinetic is plotted on a logarithmic scale for better clarity. 


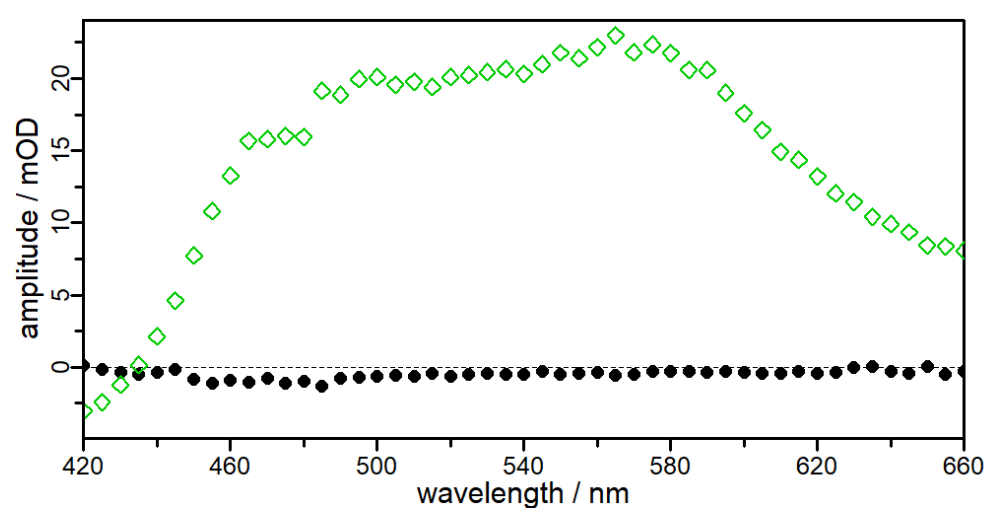

Figure S8.1. Decay-associated spectra of the global fits applied to the kinetic absorption data of $\mathbf{C 1}$ excited at $355 \mathrm{~nm}$ in acetonitrile. The amplitudes of the mono-exponential fit function $F(\lambda, t)=\sum_{i}^{1} c_{i}(\lambda)$. $\exp \left(-t / \tau_{i}\right)+c_{0}$ are displayed in green squares $\left(c_{1}\right)$ and in black dots ( $c_{0}$, long-living component) with time constants $\tau_{1}=\mathbf{2 0 . 6} \mu \mathrm{s}$.

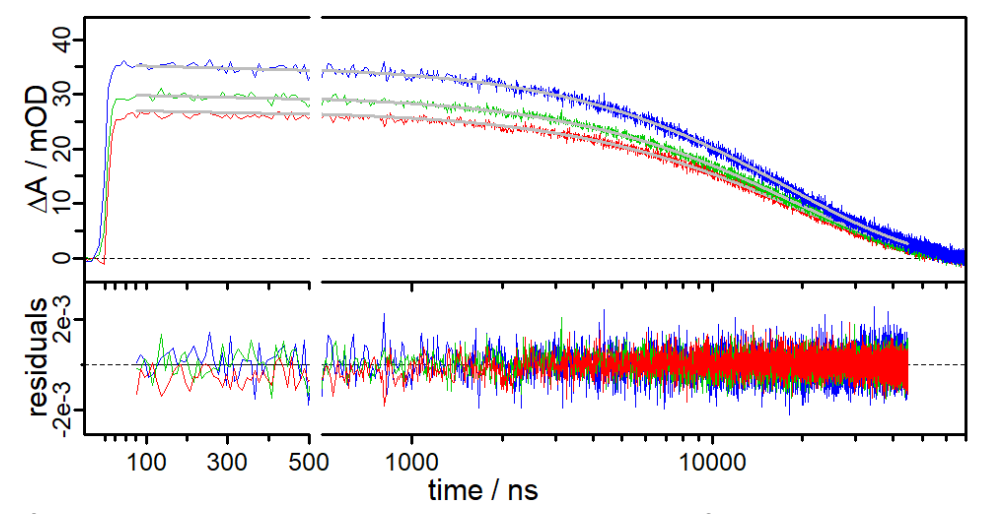

Figure S8.2. Kinetics of the transient absorption measurements of $\mathbf{C 1}$ excited at $355 \mathrm{~nm}$ in acetonitrile at 470 (red), 500 (green) and $570 \mathrm{~nm}$ (blue). The grey lines represent a mono-exponential fit with $\tau_{\mathbf{1}}=\mathbf{1 8 . 0}$ $\mu s$. The decay times were obtained by a global analysis of the measured data $\triangle O D$ with the function $F(\lambda, t)=\sum_{i}^{n} c_{i}(\lambda) \cdot \exp \left(-t / \tau_{i}\right)+c_{0}$, with the probe wavelength $\lambda$, the delay time $t$ and $c_{0}$ as long-living component. The residuals are plotted below.

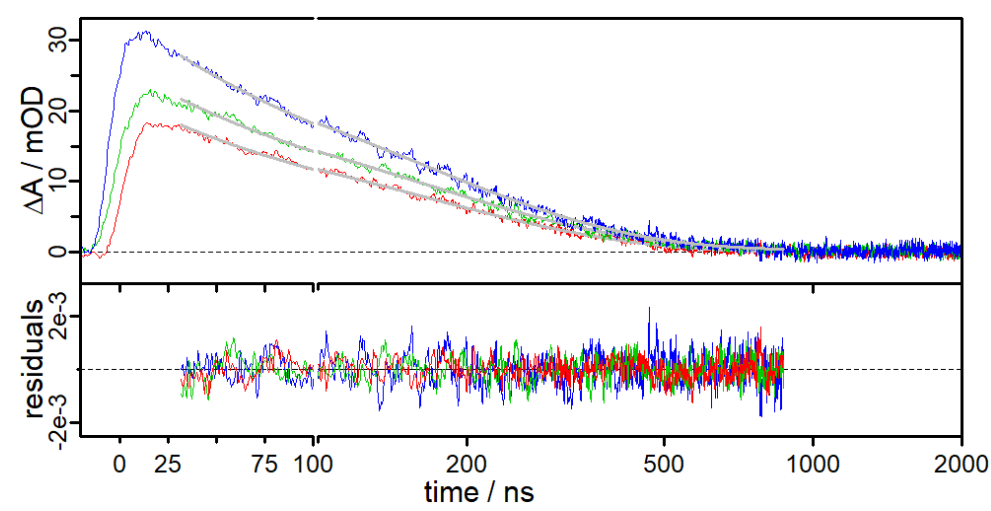

Figure S8.3. Kinetics of the transient absorption measurements of $\mathbf{C} \mathbf{1}$ excited at $355 \mathrm{~nm}$ in acetonitrile/ $\mathrm{H}_{2} \mathrm{O}$ $(10 \% \mathrm{v} / \mathrm{v})$ at $470(\mathrm{red}), 500$ (green) and $570 \mathrm{~nm}$ (blue). The grey lines represent a mono-exponential fit with $\tau_{1}=170 \mathrm{~ns}$. The kinetics are plotted on a linear $(0-100 \mathrm{~ns})$ and logarithmic scale (>100ns) for greater. Please note that, due of the weak signals, no complete spectra have been recorded. 


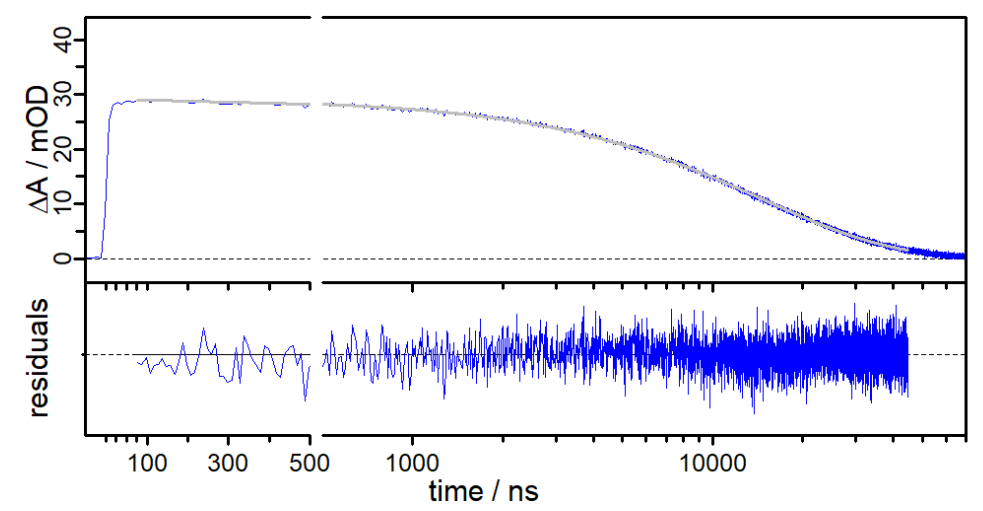

Figure S8.4. Kinetics of the transient absorption measurements of $\mathbf{C 1}$ excited at $532 \mathrm{~nm}$ in acetonitrile at $570 \mathrm{~nm}$ (blue). The grey lines represent a mono-exponential fit with $\boldsymbol{\tau}_{\mathbf{1}}=\mathbf{1 4 . 7} \boldsymbol{\mu \mathrm { s }}$. The decay times were obtained by a global analysis of the measured data $\triangle O D$ with the function $F(\lambda, t)=\sum_{i}^{n} c_{i}(\lambda)$. $\exp \left(-t / \tau_{i}\right)+c_{0}$, with the probe wavelength $\lambda$, the delay time $t$ and $c_{0}$ as long-living component. The residuals are plotted below. 